\title{
Professional culture compatibility and performance in international joint ventures: A Chinese experience
}

\author{
By \\ Xiangfu Gan
}

\begin{abstract}
A thesis
Submitted to the Victoria University of Wellington

in partial fulfillment of the

requirements for the degree of

Master of Management Studies
\end{abstract}

Victoria University of Wellington

2008 


\begin{abstract}
This research was influenced by Sirmon \& Lane's (2004) model of cultural differences and international alliance performance. Sirmon \& Lane's model introduced the concept and importance of partners' professional culture compatibility in international alliances. However, to date, their model lacks empirical testing. This research therefore took the study further by empirically investigating the influence of professional culture compatibility between partners and international alliance performance by using a selected sample of Sino-Foreign joint ventures in China. The findings overall support Sirmon \& Lane's (2004) model that (1) Partners from similar national cultures experience lesser differences in their professional cultures as opposed to partners from diverse cultures; and, (2) Professional culture differences between partners negatively influence the overall performance of international joint ventures. However, this research also argues that the relationships shown in Sirmon \& Lane's (2004) model are not as straightforward as was previously proposed, and the findings suggest several additional factors that contribute to the relationship between partner professional culture compatibility and international alliance performance.
\end{abstract}




\section{Acknowledgements}

Many people have helped me throughout the completion of this research. I would like to formally thank those people for their support.

First, I would like to thank my Director Dr. Urs Daellenbach. I have never studied management before, and it was Urs who accepted me and provided me with the wonderful opportunity to become one of his students. During my time at Victoria, Urs has shared much of his time, energy, and knowledge to help me. In particular, Urs gave his full support and much of his personal time to help me with writing this thesis. It is my honor being one of Urs's students, and I am extremely grateful for his leadership and support.

In China, Mr. Wang and Mr. Wei from the Foreign Investments Bureau in Wuhan, Mrs. Wang from the Wuhan Chamber of Commerce, Mr. Andrew White from New Zealand Trade \& Enterprise (Shanghai) office, and Ms. Vivian Zhang from Skellerup (Shanghai) office, made this thesis possible. They introduced people, recommended companies, and gave excellent suggestions to help me while I was in China conducting this research. Without their help, it would not be possible for me to find suitable interview participants. 
I would also like to thank my friends and colleagues. Hong, I would particularly like to thank you for managing Wigram Manor while I'm away in China. Your support made it possible for me to take time out to do this research. Helen, Carol, Johnny, and Brian, I would like to thank all of you for looking after the business while I'm away.

Finally, this acknowledgement would not be complete without paying my gratitude to my parents. I thank you for all your trust, love and support. 


\section{Table of Contents}

\section{Chapters}

1. Introduction 1

2. Literature Review: Cultural levels and differences in International Alliances 6

2.1. The influence of national and organizational culture distance on $\begin{array}{ll}\text { international alliances } & 8\end{array}$

2.2. The concept of professional culture 14

Model 1: Sirmon \& Lane's (2004) model of cultural differences and $\begin{array}{ll}\text { international alliance performance } & 17\end{array}$

2.3. Initial research questions 23

3. Literature Review: International joint ventures in China 25

3.1. Reasons for selecting International joint ventures in China 27

3.2. Culture compatibility in Sino-Foreign joint ventures in China 28

3.3. Restatement of research questions 33

4. Literature Review: Chinese National Culture 37

4.1. Confucianism 38

4.2. Daoism $\quad 40$

4.3. Buddhism 42

4.4. Major culture characteristics in China 43

4.5 Comparisons with western business cultures 46

Table 1: Comparison of major culture differences between China and the West 48

4.6 Final restatement of the research questions 49

5. Research Methodology 51 
Table 2: Framework of influential Chinese cultural characteristics in the

7.1. Relationship between related complementary resources and the value creating activity

7.3. The influence of partner employees' professional culture compatibility on the relationship between related complementary resources and value creating activity

Model 3: Integrated model of professional culture compatibility and international joint venture performance 
References 


\section{Introduction}

Firms use international alliances as their strategy for entering foreign markets mainly because of culture distance (Hollensen, 2004). Cultural distance, defined by Luostarinen (1980), is "the sum of factors creating, on the one hand, a need for knowledge and, on the other hand, barriers to knowledge flow and hence also for other flows between the home and the target countries" (pp. 131-132). This distance is often the primary factor influencing a firm's choice over a more committed entry mode, for example, the choice of forming an alliance over wholly-owned subsidiaries (Hollensen, 2004).

International joint ventures are the most popular form of international alliance and as such, these ventures are a rapidly growing organizational form that has received interest from researchers from a variety of academic backgrounds (Hollensen, 2004; Yan \& Gray, 1994). International joint ventures can offer opportunities for partners to share and leverage partner resources such as knowledge and skills (Hagedoorn, 1993). International joint ventures can assist firms to share cost and risks, to enter new markets, to increase their capabilities, and to seek innovations by combining knowledge and skills from different areas of science and technology (Hollensen, 2004). 
Despite the benefits, international joint ventures have a high failure rate. Researchers have reported that international joint ventures are short term and unstable organizational forms (Inkpen \& Beamish, 1997; Yan, 1998; Yan \& Gray, 1994). According to past studies, the cause for international joint ventures' instability can be broken into two major categories: (1) Control, trust and bargaining power (Yan \& Gray, 1994; Inkpen \& Beamish, 1997), and (2) Cultural compatibility (Sirmon \& Lane, 2004; Li et al., 2001; Pothukuchi et al., 2002).

The primary focus for this research is on culture compatibility between international alliance partners and its influences on alliance performance, although it is acknowledged that culture compatibility may affect control and trust. Specifically, the aim of this research is to examine professional culture compatibility between international joint venture partners and its influence on the joint venture performance.

The concept of professional culture influence on alliances was recently introduced by Sirmon \& Lane (2004). They proposed:

"Differences in the professional cultures of the employees involved in the alliance's primary value-creating activities will have more influence on the relationship between related complementary resources and the effectiveness of the alliance's value-creating activities than differences in the partners' organizational or national cultures.” (p. 315) 
The lack of empirical testings of the above proposition provides an opportunity and gap within which this research can further investigate Sirmon \& Lane's arguments. Therefore, the article by Sirmon \& Lane (2004) provides the fundamental thinking behind this research, with their research and key constructs being reviewed in detail in the next chapter.

There are several reasons for my choice of this topic. First, as discussed, this is a new area, only recently being theorized by Sirmon \& Lane (2004). As a result, this area may offer significant theoretical contributions to the existing studies concerning culture and international alliance performance. Second, in addition to theoretical contributions, this research can also add new knowledge for managers in explaining the influence of partner culture on alliance performance, and thus hold practical contributions as well. Finally, and most important for me personally, I am a businessman, born in China, but raised in New Zealand. My family and I have always had business relationships with China because of our bilingual abilities. However, despite these language advantages, dealing with China has not always been easy. I have experienced many problems in the past due to bad communication and I have also heard many accounts of some Sino-Foreign joint ventures in China that have failed due to differences and misinterpretations of development intentions. These personal experiences have generated enormous interest for me in the topic of culture and the performance of international alliance, particularly with international alliances 
in China. As a result, I selected China as the research location. This choice will be further justified in Chapter 3.

This research is broken down into two phases. Both phases used qualitative methods. Data were gathered from the interviews of eight local managers and the case analysis of three Sino-Foreign joint ventures in China. Phase 1 investigates the construct of professional culture by interviewing eight local managers from three industry sectors. Phase 2 investigates the influential relationship between professional culture and international joint venture performance by analysing three Sino-Foreign joint venture case studies in the manufacturing sector. This will be discussed in detail in subsequent chapters.

The following chapters will first review literatures from the three major areas related to this research: Chapter 2 reviews past studies concerning culture's influence on international alliances. In this chapter, the concept of professional culture will be introduced in detail along with identifying research gaps and research questions. Chapter 3 reviews past literatures focusing on joint ventures in China. This chapter discusses available joint venture studies in China, additional research gaps, and a restatement of the research questions. Chapter 4 reviews studies on the Chinese national culture. The review of Chinese national culture is important to this research because according to Sirmon \& Lane (2004), understanding national culture is a prerequisite for the analysis of professional culture. This chapter explains the major 
culture factors influencing the contemporary business environment in China, and concludes with a final restatement of the research questions.

Chapter 5 explains the research methodology employed in both phases. Chapters 6 and 7 present findings for both phases individually. Chapter 8 covers analysis and discussion of the findings, research limitations and, finally, a conclusion with managerial and theoretical implications. 


\section{Literature Review: Cultural Levels and Differences in International Alliances}

Cultural compatibility has always been a widely researched topic in the field of international business management, and it is often viewed as crucial to alliance success (e.g., Sirmon \& Lane, 2004; Parkhe, 1991; Pothukuchi et al., 2002). In the past, scholars have studied this topic extensively and have categorized culture between alliance partners into two major levels: (1) national/social culture, and (2) sub-national, often described as organizational culture.

This chapter discusses past studies concerning these culture levels and their influence on international alliance performance. The highlight of this chapter introduces the concept, which was proposed by Sirmon \& Lane (2004), of professional culture and its relative influence on partner performance in international alliances.

There are several definitions for culture and cultural levels. For example, Triandis (1972) defined culture as:

“...an individual's characteristic way of perceiving the man-made part of one's environment. It involves the perception of rules, norms, roles, and values, is influenced by various levels of culture such as language, gender, race, religion, place of residence, and occupation, and influences interpersonal behavior." (p.4) 
A similar definition was offered by Hofstede (1984). Hofstede (1984) defines culture as:

“...the collective programming of the mind which distinguishes the members of one human group from another." (p. 260).

Hofstede's definition embraces different layers of culture, yet is less complex in comparison to Triandis's (1972) definition. Furthermore, Hofstede suggests that culture, while often reserved for nations or regional groups, can also apply to other human groups such as organizations or professions. Hosfstede's definition will be employed by this research.

This chapter will first review literatures concerning the influence of national and organizational culture distance on international alliance performance. Then, the concept of professional culture, its importance and its influence on international alliances will be introduced. Finally, this chapter will conclude with a set of research questions. 


\subsection{The influence of national and organizational culture distance on}

\section{International Alliances}

Culture reflects shared meanings, norms and values (Karahanna et al., 2005), and it can be applied to nations, ethnic and regional groups, as well as other human groups such as organizations and professions (Hofstede, 1984). Culture is not a separate entity from the individuals that constitute a group, but reflects those people and their values (Karahanna et al., 2005).

National differences comprise "the single greatest impact upon cultural value orientations and represent the highest level of cultural aggregation" (Sparrow \& Wu, 1998: p. 26). National culture influences individual values, beliefs and behaviors within a national boundary (Hofstede, 1984). It represents a system of values and shared norms providing meanings as to how things are (Terpstra \& David, 1991). Such shared values can form from early childhood experiences, education and religion (Derr \& Laurent, 1989).

As noted earlier, international alliances between culturally distant partners are viewed as short term, unstable organizational forms (Inkpen \& Beamish, 1997; Yan, 1998; Yan \& Gray, 1994). International alliances have been argued to be ineffective in resource sharing, communication and co-operation due to partners' culture differences (Li et al., 2001). These differences provide considerable negative influence on 
alliance performance (Parkhe, 1991; Pothukuchi et al., 2002, Sirmon \& Lane, 2004; Li et al., 2001).

Lane \& Beamish (1990) argued that international alliance problems are often a consequence of the influence of national culture differences on management systems and individual behavior. This argument is supported by a number of studies such as Chen et al. (1998) and Morris et al. (1998), who suggest that areas such as expressive motives, and systems for co-operation and problem solving differ significantly between individualistic and collectivist cultures. In international alliances, diversity of cultural characteristics between partners can create barriers for effective co-operation (Parkhe, 1991).

Differences in partners' national culture have the potential to challenge and disrupt the successful development of the international alliance. These challenges could form a chain reaction of problematic issues. For example, Hitt et al. (1995) suggest that national culture differences have the potential to disrupt partners' accurate interpretation of each other's intentions due to the lack of a basis of shared understanding. Furthermore, partners may incur problems in effective communication when partners have different understandings of success and effective problem solving methods (Henderson, 1975; Rao \& Schmidt, 1998). Trust and control mechanisms may differ between partners from collective and individualistic cultures (Yan \& Gray, 
1994), and also effective knowledge and resource sharing will suffer when partners lack a common ground for shared values and norms (Li et al., 2001).

However, not all studies support that national culture is a definite negative influence on alliance outcomes. For example, Very et al. (1996) suggested that national culture differences between international alliances partners can be a positive factor because managers tend to understand that disputes may occur when dealing with partners from foreign countries. Thus, these managers may be willing to spend more effort in international alliances to prevent likely issues such as misunderstandings and bad communication. Therefore, in such circumstances, differences in partners' national culture may improve alliance communication and co-operation (Park \& Ungson, 1997).

Some inconsistent results from past research illustrate the complexity when analysing the influence of national culture differences on alliance outcomes. According to Hofstede (1984), many subcultures exist within a national boundary, and subcultures will emerge with their own distinctive, but interrelated patterns, language, values and norms to the dominant culture. Thus, studies such as Pothukuchi et al. (2002) suggest narrowing down the focus from a dominant culture (e.g. national culture) to subcultures such as organizational culture, to more accurately analyse the influence of culture on international alliance performance. 


\section{Organizational Culture}

A recent study by Karahanna et al. (2005) suggests that different cultural levels in an organizational setting consist of different balances of two critical components: value and practice. According to Karahanna et al. (2005), "values refer to relationships among abstract categories that are characterized by strong affective components and imply a preference for a certain type of action" (p. 5). Values are formed through past experiences such as childhood and education, providing fundamental assumptions of how things are (Erez \& Earley, 1993).

Practices, on the other hand, are learned later through socialization particularly in workplaces (Karahanna et al., 2005). Practices provide individuals with ways of doing things, such as facts about the world, how it works, and causal effect relationships (Hofstede, 1991). Practices can change through life, but values acquired from childhood experiences and education, on the other hand, are difficult to change (Karahanna et al., 2005; Erez \& Earley, 1993).

Karahanna et al. (2005) argue that various culture levels have different balances of values and practices. For example, national cultural differences for alliance firms are composed more of differences in values than in practices. However, the balance of values and practices changes when applying to subcultures, where practices may become more predominant. Organizational culture, on the other hand, primarily involves organizational practices and attitudes (Karahanna et al., 2005). 
Organizational culture provides a common norm to its members regarding what are appropriate attitudes and practices (O'Reilly \& Chatman, 1996). Organizational culture differences among partners were considered by a number of studies to be a major influential factor on international alliance performance, even more influential than national culture (Pothukuchi et al., 2002; Park \& Ungson, 1997; Brown et al., 1988).

These studies suggest that alliance partners differ primarily in the ways of their management practices, and "differences in practices represent conflicting expectations and incompatible organizational processes" (Pothukuchi et al., 2002: p. 247). International alliances are formed to combine or share knowledge and resources not currently available in one's nation (Hollensen, 2004). However, a decrease in satisfaction and effectiveness of such interactions will restrain the initial purpose of the relationship. Studies such as Brown et al. (1988) argue that partners can be unsatisfied with the alliance performance due to organizational culture differences, because partners with organizational culture differences may require spending significant time and energy to establish proper routines and practices for effective sharing and communication. Thus, Park and Ungson, (1997) argue that partner organizational culture differences can result in high cost and low outcomes when compared with partners from similar cultures. 
According to Pothukuchi et al. (2002) and Sirmon \& Lane (2004), organizational culture exists within the national boundary, and national culture can have great influence on the shaping of organizational culture. Comparing with partners' national culture differences, studies such as Sirmon \& Lane (2004) and Pothukuchi et al. (2002) argue that organizational culture difference between partners can generate a stronger direct influence on alliance performance, that "organizational culture provides more proximal cues for organization members' behaviour than does national culture because it provides members with an organizational identity, and facilitates collective commitments" (Sirmon \& Lane, 2004: pp. 310-311).

Despite the arguments from the studies cited above concerning cultural influence on alliance performance, Sirmon \& Lane (2004) and Karahanna et al. (2005) argue that many have neglected the fact that organizational culture is not the only subculture within an organizational setting. Culture can be reflected in several levels, including the national level, the organizational level and the professional level (Hostede, 1991; Karahanna et al., 2005). Professional culture is another important culture level within any organizational setting (Trice \& Beyer, 1993; Karahanna et al., 2005). Professional culture according to Karahanna et al. (2005) stands in between national and organizational culture levels: "professional culture implies the acquisition of both values and practices, whereas organizational culture is composed primarily of shared perceptions of organizational practices and, to a lesser extent of values." (p. 7). This implies that professional culture influences managerial behaviors through both its 
values and practices, whereas organizational culture influences managerial behaviors primarily through just organizational practices.

The influence of professional culture on international alliance performance has received little attention from past empirical studies, yet such a culture level, according to studies such as Karahanna et al. (2005) and Sirmon \& Lane (2004), appears to be an important influence on managerial behaviors and attitudes.

\subsection{The Concept of Professional Culture}

Professional culture is associated with educational opportunities and a person's occupation or profession (Hostede, 1991). Individual work behaviors may be influenced by values and norms derived from a mixture of all culture levels (Karahanna et al., 2005). Professional culture represents "the most highly organized, distinctive, and pervasive sources of subcultures in work organizations... Members of a professional culture share a 'consciousness of kind' that not only encompasses functional understanding, but also includes the sharing of emotional demands and social identity" (Trice \& Beyer, 1993: p. 178). According to Trice \& Beyer (1993), distinct professional cultures should exist in most work positions in an organization (e.g. Marketing, R\&D, Accounting etc). 
Drawing on past studies, Sirmon \& Lane (2004) took the research of cultural influence on international alliance further by narrowing down the analysis, focusing on the concept of professional culture. Their study represents the fundamental thinking behind the research undertaken here.

Sirmon \& Lane (2004) argue that in terms of cultural influence, professional cultural differences between partners in international alliances have the most negative influence on alliance performance. Differences in professional culture are more disruptive than organizational and national culture differences. This will be explained in detail in subsequent paragraphs.

Sirmon \& Lane (2004) argue that professional culture develops outside of any single organization, and cuts through organizational boundaries. However, it is nation specific:

"National culture is associated with values that affect professional activities... national culture differences lead to differences in professional culture... Professional culture exists when a group of people who are employed in a functionally similar occupation share a set of norms, values and beliefs related to that occupation. Professional cultures develop through the socialization that individuals receive during their occupational education and training. This initial socialization is then reinforced through their professional experiences and 
interactions that lead to a broad understanding of how their occupation should be conducted.” (pp. 310-311)

Therefore, according to Sirmon \& Lane, the relationship between the three culture levels (national, organizational, and professional) is that professional culture is a subculture nested inside a national dominant culture, and independent from organizational culture (Model 1).

Sirmon \& Lane (2004) suggest that when employees with different professional cultures work together in an international alliance, negative results are expected, because these professional individuals" "...occupational socialization and resulting professional cultures are distinct" (p. 312), and thus lack a basis of shared understandings to interact effectively. 


\section{Model 1:}

Sirmon \& Lane's (2004) model of cultural differences and international alliance performance. Thickness of arrows indicates the relative strength of the relationship.

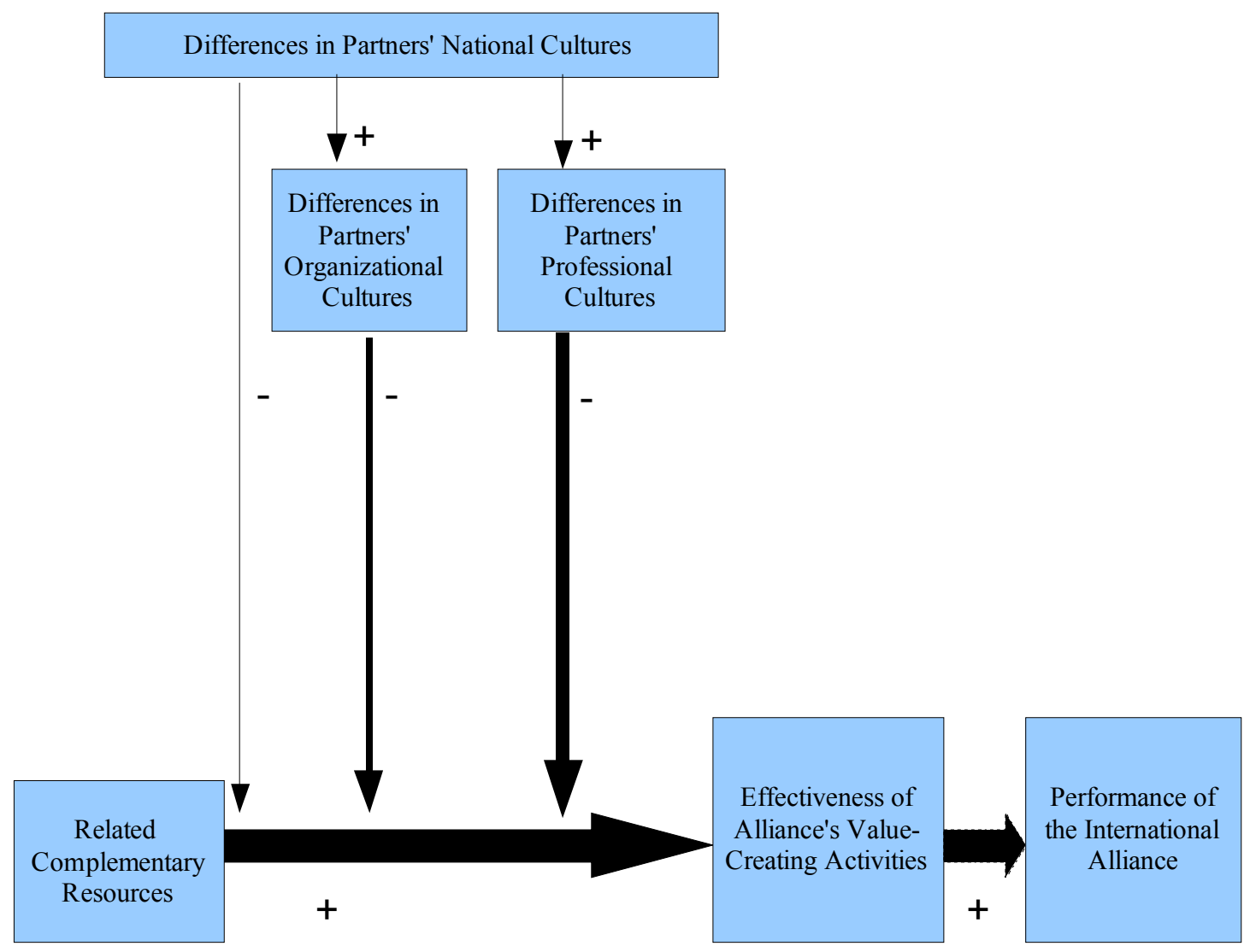

Source: (Sirmon \& Lane, 2004: p. 307)

To overcome obstacles created by culture differences, some studies suggest that partners should focus their energy on establishing practices and routines that can assist with the development of adequate communication, shared knowledge and understandings (Pothukuchi et al., 2002; Li et al., 2001; Hitt et al., 1995; Parkhe, 1991). However, to completely overcome professional culture differences may be 
difficult even with developed routines because these individuals are likely to have distinct preferences in problem solving and value creating techniques. Attempting to resolve the differences in problem solving or value creating approaches can create additional problems for the joint venture (Sirmon \& Lane, 2004). For example, if members from both partners change their professional understandings from preferred problem solving approaches, partners' valuable tacit knowledge may no longer benefit the alliance (Sirmon \& Lane, 2004). In such situations, the alliance will suffer the loss of significant knowledge and expertise from the partner members. This then reduces the likelihood of effective sharing of complementary resources, which diminishes the initial purpose of the alliance formation.

As shown in Model 1, culture differences negatively influence the relationship between the effectiveness in sharing partners' related complementary resources and the smooth running of the alliance's value creating activity, and as a result, negatively influence alliance performance. The presence of complementary resources across international alliance partners is critical in the motivation to form international alliances (Sirmon \& Lane, 2004; Walff \& Reed, 2000).

A number of studies indicated that complementary resources, both tangible and intangible, are required for alliances to achieve optimal results. (Das \& Teng, 2000; Walff \& Reed, 2000). For example, Walff \& Reed (2000) have found the complementarity of joint venture resources can produce positive results where both 
partners can be satisfied. Complementary resources allow firms to lift their own resources for performance gains. Lu \& Beamish (2001) argued that firms entering foreign markets will experience better performance when they form alliances with partners possessing relevant local knowledge, especially for small to medium sized enterprises where resources are often limited.

In contrast, Sirmon \& Lane (2004) argue that not all complementary resources can lead to positive outcomes. There are several studies supporting that the presence of complementary resources alone in international alliances is not enough for a positive outcome (Caloghirou et al., 2003; Johnson et al., 1996). For example, as illustrated by Sirmon \& Lane (2004), Caloghirou et al.'s (2003) study of international research alliances showed no positive connection with the presence of complementary resources and alliance performance. Johnson et al.'s (1996) study of U.S - Japanese alliances found that complementary resources allowed more trust from the U.S partner but not their Japanese counterpart, as measured by their perceptions of success (Sirmon \& Lane, 2004).

From these arguments and contradictory results, Sirmon \& Lane (2004) proposed that complementary resources alone do not always positively influence alliance's performance because not all partner resources are relevant to the alliance's primary value creating activity. According to Sirmon \& Lane (2004), the effective running of alliance's primary value creating activity is "a precursor of alliance performance, but 
that such primary value creating activities are specific to the purposes of specific international alliances" (p. 308). Thus only when partners' complementary resources are related to the alliance's primary value creating activity can they positively influence alliance performance.

Furthermore, Sirmon \& Lane (2004) emphasized the need for further understanding of partners' employee interactions in the value creating activities of the alliance. Not only related complementary resources but also the complementarity and effective interaction of partner employees can increase the current understandings of international alliance performance (Pothukuchi et al., 2002; Sirmon \& Lane, 2004). As a result, this raises the importance of individual professional culture compatibility in international alliances.

Thus, Sirmon \& Lane (2004) proposed:

\footnotetext{
“The complementarity of partners' resources positively affects alliance performance only when those resources are related to the primary value-creating activities of the international alliance, and when the employees involved in those activities interact effectively.” (p. 309)
}

Despite Sirmon \& Lane's (2004) arguments with respect to professional culture compatibility between international alliance partners, a major limitation in their article is the lack of any empirical testing. This limitation therefore has provided a research 
gap and an opportunity to further investigate this topic. In addition, according to Sirmon \& Lane's model, it is suggested that there is no direct relationship between the influence of organizational culture and professional culture in an alliance setting. However, studies such as Hofstede (1991) and Karahanna (2005) suggest that cultural levels are in many ways interrelated to each other in respect to values and practices; therefore, it appears logical to argue that the relationship between organizational and professional culture may not be as independent as it was proposed by Sirmon \& Lane's model.

Based on the above research gap, the purpose of this research is to take Sirmon \& Lane's (2004) study further by investigating the relationship between partners' professional culture compatibility and alliance performance, which also includes the relationship between partners' complementary resources and alliances' primary value creating activities. This research, however, will not simultaneously examine the three cultural levels (national, organizational, and professional) to determine which culture level has the most influence on international alliance performance. Instead, the primary focus for this study is on professional culture, a choice that will be justified in subsequent paragraphs.

According to a number of studies (e.g., Pothukuchi et al., 2002; Hofstede, 1984; 1991; Sirmon \& Lane, 2004; Karahanna et al., 2005), an understanding of national culture appears to be a prerequisite for understanding its subcultures. Therefore national 
culture and its relationship with professional culture need to be analysed to adequately understand the construct of professional culture.

This research will not investigate aspects of organizational culture and their influence on international alliance performance. There are several reasons for this. First, according to Sirmon \& Lane (2004) and Trice \& Beyer (1993), professional cultures are not limited to any organizational boundary but are bounded within a given nation. Therefore, professional culture is, in fact, likely a 'product' of national culture but not organizational culture. This argument suggests the need to investigate national culture, and not necessarily organizational culture, to better comprehend professional culture.

Second, past studies have treated national culture and organizational culture as separate constructs with a variety of different factors to measure, test, or explore (Parkhe, 1991; Pothukuchi et al., 2002). Given the time and financial constraints associated with a Master's thesis, it is not feasible to investigate all of the cultural features described above. As stated earlier, questions exist about the independent relationship between organizational and professional culture as proposed by Sirmon \& Lane's (2004) model. This research will instead try to uncover layers of this relationship through investigating the construct of professional culture, rather than initiating a full study on the relationship between organizational and professional culture. Thus, the primary focus for this research is to investigate the relationship, as 
illustrated by Sirmon \& Lane's (2004) model, between professional culture and international alliance performance.

\subsection{Initial Research Questions}

Because this topic is relatively new with limited relevant previous studies available, I divided this research into two phases to more accurately investigate and understand the relationships presented in Sirmon \& Lane's (2004) model. Phase 1 investigates the construct of professional culture. Phase 2 investigates the influential relationship between professional culture and international alliance performance.

Therefore, the research questions are:

Phase 1: Do distinct professional cultures exist? If so, what is the relationship between a national culture and its professional cultures?

Phase 2: Will professional culture differences between partner employees in an international alliance setting negatively influence the overall performance of the alliance?

a: Will professional culture differences between partners' employees in an international alliance setting negatively influence the effective sharing and combining of partners' related complementary resources? 
b: Will professional culture differences between partners' employees in an international alliance setting negatively influence the effectiveness and smooth running of the alliance's primary value creating activity?

Data for this research were gathered from samples of Sino-Foreign joint ventures based in China. Choices for selection of China as the research destination and joint ventures as the form of international alliance under investigation will be justified in the next chapter. The following chapters also present relevant details from previous studies on international joint ventures in China and Chinese national culture. 


\section{Literature Review: International Joint Ventures in China}

This chapter will firstly present reasons for selecting Sino-Foreign joint ventures in China as the data collection sample for this research. Secondly, past literatures concerning culture's influence on international joint ventures in China and additional research gaps will be discussed, and finally this chapter will restate the research questions presented in the previous chapter.

Chinese are all over the world, amounting to almost quarter of the world's population. "China is an awakening giant that has caught the attention of every player aspiring to get a piece of the largest emerging market in the history of civilization" (Qu \& Zhang, 2005: p. 32). China has experimented with alternative models to generate rapid economic growth. It is now one of the most popular investment destinations, and it will become one of the greatest markets in the world (Huang, 2004). Central to the Chinese success has been the liberalization of trade and investment policies to attract foreign direct investments, which has led to unprecedented growth in foreign direct investments in China since 1972 (Child \& Tse, 2001).

Despite China's spectacular growth, international joint ventures in China have continued to pose serious problems with regard to their level of performance (Beamish, 1993). As a result, more scholars have been studying international joint ventures in China in order to seek solutions and understandings of this unique 
economic entity. Studies have examined alliance performance and success from a variety of perspectives. Some studies examined entry mode effectiveness and motives using joint ventures as an investment vehicle into the China market (Tse et al., 1997; Luo, 1995; Luo et al., 2001; Pan, 1997). Others examined the influence of bargaining power, management control, and ownership structures between partners on joint venture performance (Yan \& Gray, 1994; Pan, 1996). Some have investigated foreign investment failures by analysing co-operative strategies used in Sino-foreign alliances (Pan \& Tse, 1996), while cultural compatibility and its influence on joint venture performance (Li et al., 2001; Luo, 1997) have been considered by others.

As shown, past studies concerning foreign businesses in China have been focused on a broad and diverse range of issues concerning the successes and failures of foreign investments. Many of these studies have generated some inconsistency in results. For example, Luo (1995) argued that joint ventures are the most appropriate form of foreign investments in China due to an ability to better acquire local knowledge, while Pan (1997), on the other hand, indicated that wholly owned foreign subsidiaries have better performance than joint ventures in China. In contrast, studies such as Pan \& Chi (1999) suggest first mover advantages, where others such as Li et al. (1999) found no support for early entry advantages in China. The conflicting results in these studies have suggested that researchers need to consider additional factors when examining and explaining the behavior and performance of foreign businesses in China. As pointed out by Li et al. (2001), the contradictory results might have resulted from the 
lack of consideration of important institutional or environmental factors such as social cultural compatibility between partners and its effect on alliance performance.

Of the limited studies examining partner culture influences on international alliance performance in China, little or no research has been conducted concerning the influence of professional culture compatibility and international alliance performance in China. The lack of knowledge in this area represents a potential theoretical contribution of this research.

\subsection{Reasons for selecting International Joint Ventures in China}

China was selected as the research location for several reasons: Firstly, it is more worthwhile from a research perspective to investigate culture compatibility issues between diverse cultures rather than similar cultures (Beamish, 1993; Li et al., 2001). Selecting partners from the east and the west represents such diversity in cultural backgrounds.

Secondly, China is one of the most popular destinations for foreign investments (Huang, 2004). Research in China represents an excellent opportunity to explore culture differences in international business, particularly since China's business environment and professional attitudes have been shaped by its rich and complex 
history and culture. With the tremendous increase in economic developments and foreign investments in China (Child \& Tse, 2001), this research also seeks to add contributions to practitioners seeking investments in China.

Thirdly, as stated previously, I was born in China, and I can speak Chinese Mandarin fluently. Since English is not common in China, I therefore possess some advantages in data collection comparing to a researcher without such language abilities.

Joint ventures were selected as the form of alliance to investigate because joint ventures are the most popular form of alliance in international businesses (Hollensen, 2004), and among all the investment forms, joint ventures have been the most frequently used form of foreign direct investment in China (Beamish, 1993).

\subsection{Culture compatibility in Sino-Foreign joint ventures in China}

As discussed in the previous chapter, culture differences in international alliances have been studied by a number of academics - however, there is relatively little understanding and examination of cultural compatibility in joint ventures in China (Lin, 2004). The literature review found that only a few existing studies focus primarily on the influence of cultural differences between international joint venture partners in China (Li et al., 2001; Lin, 2004; Tsui et al., 2006). Despite the limited 
amount of research to date, these studies have confirmed the influential importance of culture on joint venture performance in China. For example, Lin (2004) noted that culture adaptation in China is beyond simply adapting business practices, but involves the understanding of the other party from a cultural perspective, such as values and beliefs. Lin's (2004) survey of 94 Sino-U.S. joint venture managers supported the view that national cultural adaptation leads to positive performance for international joint ventures in China.

A recent study by Tsui et al. (2006) analysed organizational culture in different ownership structures in China. Although their study did not focus specifically on alliances, it provided comparative insights on organizational culture differences and outcomes between domestic firms and foreign-owned firms in China. They found that foreign-owned firms in China show a stronger emphasis on both internal integration and external adaptation values compared to domestic firms, and that this contributed to better perceived firm performance for foreign-owned firms. Their research illustrated organizational culture differences between private, state-owned and foreign-owned firms in China, suggesting differences in values across the various business approaches. In a Sino-Foreign joint venture environment, these differences can become obstacles hindering the smooth running of the joint venture (Pothukuchi et al., 2002). 
An important study that has contributed to our understanding of social-cultural influence on joint ventures in China was Li et al.'s (2001) study of 898 Sino-Foreign joint ventures. Li. et al., (2001) not only found evidence supporting that national cultural differences between partners have negative influences on joint venture performance, but they also found that economic differences between developed and developing economies can cause negative effects on joint venture success. Li et al. (2001) advised that:

"All the major overseas investors, either from East Asia or other developed areas in the world, have already established formal institutional environments during the development of their market economies. Moreover, overseas investors in China are mainly from those highly open or internationalized economies in which rules and other formal institutional elements have become very similar after decades of global competition and co-operation" (p. 116)

All foreign partners selected in Li et al.'s (2001) study were from developed economies (e.g., Britain, Taiwan, U.S, Japan, Singapore, etc). They suggested that because of the similarities in institutional environments among developed economies, the effects of culture on joint venture performances are considerably reduced when compared with emerging economies (Luo, 1997). Li et al.'s (2001) study raises not only the importance of culture understanding, but also the understanding of the degree of economic development. Their results also suggest that China joint ventures with some East Asian countries, such as Singapore and Taiwan, have gained efficiency in 
areas such as market entry, human resource management and lower capital investments. This is because these countries have similar culture background, and are able to more quickly adapt to the changing environment as opposed to Western counterparts. Therefore, in comparison to Sino-Western joint ventures, although these joint ventures often have better technological resources, they experienced lower efficiency due to culture constraints. As a result, Sino-Western joint ventures face a more complex situation, where one has to overcome obstacles created by both culture and economic differences in order to become efficient and competitive.

Other studies have also viewed economic differences between developed and developing economies as a negative influential factor for business success. For example, Lee \& Beamish's (1995) study examined Korean joint ventures with partners from developing countries, and suggested that economic differences between developed and developing countries negatively influence the smooth running of joint ventures. In addition, Child \& Tsui (2001) emphasized the importance of understanding China's economic transitions for international businesses wanting to operate there. They suggested:

"Institutional change in China is highly complex because in this formerly closed, state-dominated system, institutions have developed into a massive inter-dependent, multi-level network whose logic of operation depends as much on political influence and personal relationship as on concern for efficiency." (p.6) 


\section{Research Gaps}

From the review above, two research gaps have been identified for this thesis:

First, the above culture studies have focused primarily on the examination of national culture (e.g. Li et al., 2001; Lin, 2004) and organizational culture (e.g., Tsui et al., 2006). Little, if any, research has been carried out in China concerning the influence of professional culture differences between joint venture partners. As proposed by Sirmon \& Lane (2004), professional culture is the most disruptive of all cultural differences between joint venture partners. In addition, according to Lin (2004), the overall amount of joint venture research in China appears insufficient. Adequate understandings of joint venture issues in China require extensive research in all related areas (Lin, 2004). Thus, by studying the influence of professional culture in Sino-Foreign joint ventures, this thesis will contribute additional knowledge to current culture studies in China.

Second, much of the alliance research has been conducted in developed countries (Child \& Tsui, 2001). Child \& Tsui (2001) argue that researchers should focus also on developing economies such as China due to its heavy engagement in current international businesses and investments. As Giamartino (1991) argued “it's a broad assumption that there are similarities in economic development processes across developed and developing economies, and that would seem to be both ethnocentric and unsubstantial" (p. 92). Giamartino suggests that without extensive research in 
developing economies, any conclusion or problematic suggestion could be meaningless. Only in recent years have academics begun to emphasize the need to focus on emerging markets such as China (Luo, 1997; Yan \& Gray, 1994; Lin, 2004; Tse et al., 2006). Therefore, investigating professional culture differences between Sino-Foreign joint venture partners should contribute to our understanding of international joint ventures overall.

\subsection{Restatement of Research Questions}

To fill the above research gaps, the aim of this research is to take a closer look at cultural issues using the concept of professional culture compatibility between Sino-Foreign joint venture partners. As stated earlier, Sirmon \& Lane's (2004) model of culture differences and international alliance performance provides the fundamental thinking behind this thesis. Greater understanding of professional cultural compatibility can help to extend our knowledge and provide fresh perspectives to current alliance culture research. Moreover, Sirmon \& Lane's (2004) model requires experimental testing. Therefore, with the analyses of partners' professional culture compatibility in Sino-Foreign joint ventures in China, this research can provide additional understanding of Sirmon \& Lane's (2004) propositions. 
In addition to examining professional culture, this research will also search for relevant knowledge of China's economic development and its influence on culture. Child \& Tsui (2001) argued that understanding China's economic transition is vitally important for foreign business to succeed in China, due to rapid changes in its economic environments. Li et al. (2001) also argued that economic differences between developed and developing economies can negatively moderate the effectiveness in partners' national culture compatibility in Sino-Foreign joint ventures. These studies have emphasized the importance of China's economic development on business in China. Following Li et al. (2001), I assume that if economic developments in China influence China's national culture values, then these developments will ultimately influence professional culture. Therefore, this research will also look at the influence of the economic development factor by assessing whether relationships between China's economic development and individual professional cultures may exist.

Drawing on the literatures above, the research questions are:

Phase 1: 1. Do distinct professional cultures exist in China? If so, what is the relationship between China's national culture and professional cultures?

2. Do other factors such as the degree of economic development and economic transitional process influence national culture traits 
associated with the contemporary business environment in China? If they do, to what extent?

Phase 2: Will professional culture differences between partner employees in a Sino-Foreign joint venture in China negatively influence the overall performance of the joint venture? More specifically,

a: Will professional culture difference between partners' employees in a Sino-Foreign joint venture in China negatively influence the effective sharing and combining of partners' related complimentary resources?

b: Will professional culture differences between partners' employees in a Sino-Foreign joint venture in China negatively influence the effectiveness and smooth running of the alliance's primary value creating activity?

This research will not investigate foreign partner national cultures because (1) not all foreign partners are from the same nation, creating extensive effort and difficulties to analyse these thoroughly (that is, in the detail that China's culture will be assessed), and (2) the joint ventures under investigation in this research are all based in China, and foreign partners are attempting to adapt to the Chinese environment and culture to effectively run their joint ventures. Therefore, the Chinese national culture represents the concept that is central to understanding professional culture differences and cultural distances for these joint ventures. Finally, some recent research (Singh, 
2007) argues that national cultures alone may have less direct influence on firm performance than has previously been attributed.

To examine these questions further, it is first necessary to review literatures on national culture in China and identify what national factors contribute to its contemporary business environment. Chang \& Tam (2004) suggested that there is a distinct business culture in China, and any corporation doing business with China will have to know it and master it. The next chapter reviews China's national culture characteristics and its influence on contemporary business thinking. 


\section{Literature Review: Chinese National Culture}

China represents one of the longest civilizations on earth, with over five thousand years of history (Abdahlla, 2002). With over 1.3 billion people, China is the most populated country in the world, over one fifth of the world's population (Street \& Matelski, 2003).

The Chinese culture is influenced by several major factors, which in turn influence contemporary Chinese thinking and Chinese management (Abdahlla, 2002). The subsequent sections will first briefly discuss the three main schools of thought in Chinese culture: Confucianism, Daoism, and Buddhism. Differing to Christianity, where one cannot be both a Protestant and Catholic, the Chinese people can, and do accept Confucianism, Daoism, and Buddhism without conflict (Street \& Matelski, 2003). Secondly, the concept of family and collectivism will be introduced, and its importance in the Chinese culture will be discussed. Then, I will explain the concept of face and guanxi. Finally, based on the literatures, a general comparison between China and Western business cultures will be made. According to the literatures reviewed, a final restatement of the research questions will be presented at the end of this chapter. 


\subsection{Confucianism}

The moral teaching of Confucius began with the family and an ideal model of relationship between family members (Cummings, 1984). It then generalized this family model to an international system (the Chinese world order).

Confucius believed that Chinese society is made up of moral binding relationships, and that the individual is never independent from the society (Abdahlla, 2002). A Chinese individual's self-esteem would be achieved through maintaining the harmony of the society (Redding, 1990). To maintain social harmony, Confucianism often stresses the principle of 'reciprocity' (Redding, 1990, Abdahlla, 2002). Reciprocity is the foundation for the concept of guanxi (Luo, 1997), which will be discussed further in subsequent sections.

Confucius identified five basic relationships or the Five Cardinal Relationships called Wu Lun, as the most fundamental to a stable society (Chang \& Holt, 1991):

1. Father - Son (the relation of love)

2. Emperor - Subject (the relation of righteousness)

3. Husband - Wife (the relation of chaste conduct)

4. Elder - Younger (the relation of order)

5. Friend - Friend (the relation of faithfulness) 
The relationships above represent the structure of social responsibilities, ideally with the elder protecting the younger and the junior respecting the senior (Abdahlla, 2002; Chang \& Holt, 1991).

The Confucian social order is a respect for the past. It relies on history for knowledge and guidance (Street \& Matelski, 2003; Abdahlla, 2002). The basis of Confucian order is the family. Society is viewed as a hierarchy of roles, which contains well established values and norms guiding how people should behave toward each other (Abdahlla, 2002; Chang \& Holt, 1991; Street \& Matelski, 2003; Yum, 1991).

Although Confucianism creates a social system with incredible stability, it lacks the ability to adapt, innovate, or change. In addition, inappropriate behavior is strictly disciplined from an early age, thus resulting in respect for and dependence on elders (Chang \& Holt, 1991). As a result, tradition, particularly family tradition, became the only and true authority (Scarborough, 1998; Abdahlla, 2002).

The influence of Confucianism in China on the Chinese people is significant. Over time, billions of Chinese children have studied Confucius' principles. China's civil service examination (based on Confucius' teaching, and which existed for over two millenniums), was not eliminated until 1905 (Abdahlla, 2002). Even during the Chinese Cultural revolution (1966-1976), when Confucian principles were disapproved by the Communist Party, Confucianism still remained in the Chinese 
culture and the Chinese people, influencing every part of a Chinese person's life (Abdahlla, 2002; Street \& Matelski, 2003).

\subsection{Daoism}

Daoism, more commonly referred to as Taoism in Western terms, become popular in China during the period of Confucianism (Abdahlla, 2002). The concept of Dao originated from a philosopher called Lao Tzu, born approximately 551 BC (Gilbert, 1978).

Daoism is common to most Chinese philosophy, but the term 'Daoists' is specifically applied to the followers of Lao Tzu (Chan, 1967). The teaching of Lao Tzu included:

"Passive non-action, identification of the individual with nature, and spontaneous righteousness; it rejected verbal distinctions, categorizations, and logical argument and suggested that what seems real is often an illusion and what seems a dream may be real". (Chan, 1967: p. 30)

The Dao reads:

- A path becomes a path by walking it

- A thing is made a thing by being so-called

- Why are things so?

- They are so because they are so 
- Why are they not something other than what they are?

- They are not something else because they are not

Source: (Gilbert, 1978: p. 414)

Daoism stresses the importance of people maintaining harmony with nature (Smith, 1994; Chan, 1967). Nature is extremely important in one's life, and an 'unnatural' lifestyle would cause severe problems and sufferings (Chan, 1967). As a result, Daoism advocates the unity of human and nature, and believes that one can not survive without the other (Thompson, 1975).

Also in Daoism, mind determines all. An individual mind can only be freed if the person is able to leverage themselves from all artificial constraints such as money and power (Abdahlla, 2002).

Daoism and Confucianism make a good balance. Confucianism, on one side, argues the importance of social order and moral integrity of human beings; Daoism, on the other hand, stresses the harmony between human and nature (Street \& Matelski, 2003; Abdahlla, 2002). Despite that Confucianism and Daoism have a significant impact on the Chinese culture, the two schools of thought still did not fulfill all of Chinese peoples' spiritual needs. Buddhism later fulfilled some of the remaining spiritual needs. 


\subsection{Buddhism}

Buddhism originated in India and travelled to China in approximately 100BC (Gilbert, 1978). Buddhism in China is referred to as Mahayana Buddhism, which is different from Buddhism in India (Gilbert, 1978). With political structures already well established with Confucianism, the Chinese people focused more on the spiritual dimensions of Buddhism (Smith, 1994; Abdahlla, 2002).

As suggested by Street \& Matelski (2003), Buddhist beliefs influenced the contemporary Chinese thinking in a way that:

"if Americans claim a Judeo-Christian foundation as their guide to politics, business and personal relationships, it seems equally understandable that a core element of the Chinese worldview incorporates a spiritual dimension as well. The difference is the focus of that dimension, not the dimension itself." (p. 32)

The concept of afterlife and reincarnation were brought to the Chinese people by Buddhism. A person's future status (social, financial, family, etc.) was determined by that person's past actions (Abdahlla, 2002; Street \& Matelski, 2003). As a result, the concept of reincarnation provided answers as to why reality is cruel and why the quality of lives differ among people (Abdahlla, 2002; Chan 1967). Most importantly, Buddhism offered hope by promising great achievements if one was committed to do good and avoid evil (Abdahlla, 2002). 
As discussed, the different schools of thought live in harmony with one another. It is not uncommon to find the practices of several schools in one monastery (Street \& Matelski, 2003).

Finally, Abdahlla (2002) concluded that:

"Buddhism brought spiritualism to the Chinese culture, which complemented the more human-based schools of thought of Confucianism and Daoism." (p. 26)

\subsection{Major Culture Characteristics in China}

\section{Family and Collectivism}

According to Confucianism, the family is the basic unit of any society; a stable society would exist only if each family was constructed with harmony (Scarborough, 1998). Considering the impact of Confucianism on Chinese culture, family is of significant importance in Chinese society. The importance of family is probably the most standout culture value in China (Abdahlla, 2002).).

Historically, Chinese people survived on land and agriculture, causing immobility, thus the family became the basic unit for survival (Scarborough, 1998). As a result, trust and dependence on the family became vitally important. 
Filial piety in China directs social structure and responsibilities, and it is one of the most important culture values in controlling social behavior (Ho, 1994; Zhang \& Bond, 1998). According to the Chinese mind, every family member has the obligation to protect the family's reputation, and filial piety is often considered to be more important than other social obligations (Abdahlla, 2002). Filial piety is also associated with other Chinese culture characters such as respect for elders and tradition (Zhang \& Bond, 1998).

As a result, collectivism became a major Chinese culture characteristic. Collectivism is associated with the importance of family in Chinese culture. With the belief that the basic unit of survival depends on the group, group benefit represents the highest level of achievement (Abdahlla, 2002). Personal gain would become possible if only the group benefit was well maintained (Hui \& Tan, 1996). As a result, individual achievements are measured in terms of fulfilling one's role in the family and society (Scarborough, 1998).

\section{Face and Guanxi}

Face in China represents people's pride, reputation, and confidence (Chen, 1995). Face can be achieved from personal gains, political power, or bureaucratic position in which face is like a social currency that comes into everyday lives (Abdahlla, 2002). A person may lose face in several different ways. For example, if one fails to maintain social harmony, refuses to undertake filial obligations, or embarrass others causing 
others to lose face (Scarborough, 1998). If a person has no face in society, then the person is considered unsuccessful (Chen, 1995).

Face can also be gained in a number of ways as well. For example, face can be gained by a person if that person gives honor to another (Abdahlla, 2002). The concept of face among the Chinese is incredibly important, and face is a key component of guanxi (Chen, 1995), where Chinese people require face to develop their social networks.

\section{Guanxi}

Guanxi can be viewed as the relationship itself or the process of creating relationships (Abdahlla, 2002). Guanxi is the unofficial relationship bond between two people, and such a relationship is often based on the exchange of favors rather than friendship (Chen, 1995). As a result, a Chinese person without guanxi is considered unsuccessful and is practically isolated from the society (Chen, 1995).

There are some important aspects of guanxi. For example, based on Luo (1997) and Abdahlla (2002), first, guanxi is based on the exchange of favors, and if one fails to return a favor, this person will not only lose its guanxi and face, but also will lose its reputation. Second, Guanxi can be transferred from one to another. For example, person $A$ has guanxi with person $B$, and person $A$ can introduce someone else to person $B$ to establish guanxi (Abdahlla, 2002). Thirdly, guanxi is personal. 
Particularly in an organizational setting, guanxi does not exist among organizations, but among the individuals. Personal guanxi can be beneficial to the organization only if the person is a member (Abdahlla, 2002).

Confucianism has played an important role in the formation of the concept of guanxi. Based on Confucianism, individuals are socially related beings. Thus, working from an interdependent society, Chinese individuals ultimately put greater emphasis on the building of social relations (Luo, 1997). This is in contrast to the individualistic cultures in the West (Street \& Matelski, 2003).

In a business environment, the Chinese typically take much time and energy establishing trust prior to business transactions (Chen, 1995). The Chinese would view guanxi as unstable if it's based on neutral and objective relationships that are common in Western societies (Abdahlla, 2002).

\subsection{Comparisons with Western business cultures}

There are some significant differences between organizations in China and the West.

Despite all the different forms of organizations in China, Chinese organizations are very similar in terms of structure (Tsui et al., 2006). Traces of different culture values can be seen when comparing organizations. For example, under the influence of 
Confucianism, Chinese organizations are extremely hierarchical compared to Western organizations (Abdahlla, 2002).

Chinese organizational structure appears to be less formal compared to Western organizations. For example, specialized departments and individual duties in Chinese organizations are not as clearly defined as in Western organizations (Abdahlla, 2002; Chen et al., 1998). Also, collectivism significantly influences Chinese businesses with people diverting their focus towards groups (Nevis, 1983). On the contrary, in Western cultures the focus is primarily on individual achievements and contributions (Street \& Matelski, 2003; Morris et al., 1998). For example, the concept of 'employee of the month' can often be found in Western organizations.

Another aspect of Chinese organizations includes the leadership and decision making structure. Differing to Western organizations where decision making and leadership is distributed throughout various levels in the organization (Abdahlla, 2002), decision making in Chinese organizations is normally controlled by the main directors (Redding \& Wong, 1986; Chen, 1995). This is also associated with power and control. Power and control in Chinese organizations belong exclusively to a manager, owner, or a small group of dominant managers, where Western organizations tend to be less centralized (Redding \& Wong, 1986; Abdahlla, 2002). 
Furthermore, Chinese people tend to avoid causing others to lose face, particularly in public, and therefore communication techniques in Chinese organizations are quite different (Scarborough, 1998). Western managers tend to be more direct with expressing personal emotions, where the Chinese are more discreet (Abdahlla, 2002).

Based on the preceding review, Table 1 provides a summary of the major differences in several Chinese and Western culture characteristics

Table 1: Comparison of major culture differences between China and the West

\begin{tabular}{|l|l|l|}
\hline Characteristics & China & West \\
\hline Social Culture & Collective & Individualistic \\
\hline Economy & Developing & Developed \\
\hline Base unit in society & Family & Individual \\
\hline Management Focus & Relationship Oriented & Task Oriented \\
\hline $\begin{array}{l}\text { Power and Decision } \\
\text { Making in Organizations }\end{array}$ & Centralized & Decentralized \\
\hline
\end{tabular}

Adapted from: (Abdahlla, 2002; Hofstede, 1984) 


\subsection{Final restatement of the research questions}

Based on information gathered from the above literatures, it is appropriate to break down the initial research questions for phase 1, to specifically investigate the influential relationships of the three schools of thought (Confucianism, Daoism, and Buddhism) on contemporary Chinese businesses and professional cultures.

Therefore, the final research questions are:

Phase 1: 1. Do distinct professional cultures exist in China? If so, what is the relationship between China's national culture and its professional cultures?

1a. How do the three main schools of thought (Confucianism, Daoism, Buddhism) influence the contemporary business environment in China? How do they influence professional understandings?

2. Do other factors such as the degree of economic development and economic transition process influence national culture traits associated with China's contemporary business environment? If they do, then to what extent?

Phase 2: 1. Will professional culture differences between partners' employees in a Sino-Foreign joint venture in China negatively influence the overall performance of the joint venture? 
1a: Will professional culture differences between partners' employees in a Sino-Foreign joint venture in China negatively influence the effective sharing and combining of partners' related complementary resources?

1b: Will professional culture differences between partners' employees in a Sino-Foreign joint venture in China negatively influence the effectiveness and smooth running of the alliance's primary value creating activity?

2. Are there relationships between other factors associated with professional culture (e.g. industry recognition, economic development), and the effective sharing and combining of partners' complementary intangible resources in Sino-Foreign joint ventures? If there are, then what is the relationship?

The factors associated with the construct of professional culture in China will be discussed in Chapters 6. 


\section{Research Methodology}

This chapter presents the research methodology employed for both phases of this research. The methodology for Phases 1 and 2 will be discussed separately. Both phases employ a qualitative methodology. Phase 1 is an initial study of national and professional cultures in China. Phase 1 investigates the construct of professional culture by interviewing eight local managers from three industry sectors. Knowledge gathered in Phase 1 will then guide Phase 2. Phase 2 investigates the influential relationship between professional culture and international joint venture performance by analysing three Sino-Foreign joint venture case studies in the manufacturing sector.

\subsection{Phase 1: Initial Study}

The primary learning objective of this phase is to understand the construct of professional culture in China. Specifically, this involves understanding, from practitioners' perspectives in general, what are the most and least influential national culture characteristics on professional cultures (professional beliefs, values, attitudes) in modern China. Given the evolving nature of Chinese national culture within business in China today and the newness of the concept of professional cultures, an exploratory qualitative approach was viewed as appropriate. As illustrated by Cavana (2004), qualitative research is often inductive, which relates to the "process of 
developing a general proposition (e.g. a conceptual framework) logically based on observed facts" (p. 36). This choice of methods assisted me to gain knowledge into the relationship between Chinese national culture and professional culture.

A qualitative method (semi-structured interviews) was used because it can contribute to exploring a wide area of discussions in a flexible manner, as opposed to questionnaire surveys (Yin, 1984). More insightful knowledge can be achieved through such interviews, because researchers have the flexibility to further explore explanations or discussions (Tellis, 1997) and to engage in broader information and knowledge gathering from all related areas.

Interviews were based on the following key question areas:

1. Describe the Chinese national culture, and its relationship with the current business environment.

2. For a foreigner to invest in China, how important do you think it is for them to understand the Chinese culture? What degree of cultural understanding do you think is necessary for foreign parties to succeed in China?

3. Do you think distinct professional cultures exist in your industry? If they exist, then do you think that national culture shapes professional culture?

4. What are the main factors influencing your professional culture (Professional beliefs, values, attitudes)? 
5. Which aspects of China's national cultural philosophies and religious beliefs do you think comprise the most and the least influence in shaping your professional understandings, beliefs, attitudes, and problem solving methods etc?

6. Are there other factors contributing to how your profession should be conducted?

In-depth discussions were undertaken based on the above question areas. The purpose of the first two question areas was to discuss the importance of culture, and its effect on the current business environment. From these discussions, it was possible to gain some insight regarding the validity of this research in general.

Question areas three, four and five were used to understand influential relationships between national culture and professional culture, and also professional training and culture. These questions helped in gathering practitioners' perspectives on the concept of professional culture (according to the model proposed by Sirmon \& Lane, 2004), and thus determine if the assumptions underlying this research are valid.

The purpose for question area six was to search for other possible influential factors. The aim of this question was to explore further knowledge in this field. Knowledge from past literatures could be limited, particularly when environments are changing as rapidly as in China's recent times. 


\section{Industry Selection}

The China State Administration of Foreign Experts Affairs Annual Report (2006) indicates that manufacturing, information \& technology, and hospitality service are the three industries that attract most foreign investments in China. The majority of international joint ventures in China are based within these industries. Thus, with a view to comparing this research to other studies, preliminary findings from these three industries are likely to provide more relevant information.

\section{Industry Definition}

The three industries were defined according to common objectives of current foreign investments in China. For example, objectives for a foreign investment firm in manufacturing often were to utilize cheaper labour in China (Yan \& Gray, 1994) along with other resources to develop both within and outside of China's market (Luo, 1997). This way, by setting up joint ventures in China, foreign firms can secure their global competitiveness (e.g. in product price, profit margin etc) and potentially grow further by gaining access to the Chinese marketplace (Luo, 1997).

- Manufacturing Industry. Firms manufacturing global products. In other words, products not restricted to only the domestic market, e.g. shoes, clothing, or other worldwide commodities.

- Hospitality Industry. Selections include all firms with current developments in this industry. Constant increases in China's Gross Domestic Product (GDP) 
have resulted in the need for rapid development in the service market (The China State Administration of Foreign Experts' Affairs Annual Report, 2006). Therefore, no restrictions are given to this industry because any developing firm within this industry has the potential to create alliances/joint ventures internationally.

- Information Technology (IT). Again, this includes all firms with current developments in this industry. Therefore any developing firm within this industry has the potential to create alliances/joint ventures internationally.

\section{Selection Criteria}

Selection criteria were based on the common cooperation structures of Sino-Foreign joint ventures or alliances in China. According to Yan \& Gray (1994), Child \& Tse (2001), and Shenkar \& Ronen (1987), the most common cooperation structure for international alliances in China is where the foreign partner provides technology (e.g. advanced technology, R\&D, global support, etc.) and their Chinese counterpart provides complementary resources (e.g. labour, land/sites, natural resources, local market access, etc.). Thus, if a local firm wishes to align with a foreign firm, it must be of a reasonable size with sufficient resources to (1) attract foreign investments, (2) comprise certain capabilities or potential to compete both locally and internationally (Luo, 1997). However, it is difficult for me to judge the attractiveness of local Chinese firms in the international market. I therefore selected firms that had previous 
dealings with the international market (e.g. export, import, attended global conventions, etc.).

As for interviewee selection, because this research topic concerns managerial levels, interview participants must currently be in middle to senior management positions. In addition, they must have over three years of experience in the current industry in order to assist with in-depth discussions related to their profession's culture.

All managers were personally interviewed. The interviews took place in the managers' workplace/offices. The duration of each interview was approximately 45 minutes, and in total the eight managers were interviewed: four from the hospitality service industry, two from the manufacturing industry, and two from the IT industry. Given its exploratory nature, this sample size seemed large enough to identify some key issues relevant to this research, that is, key national culture factors and the potential for separate professional cultures to exist. While more interviews would have been desirable, initial difficulties in identifying willing participants (discussed below) made it difficult to extend the duration of Phase 1 of this research.

\section{The Use of Guanxi}

My initial efforts to contact potential interviewees through emails and phone calls were unsuccessful. Most of the managers showed no interest in participating. I then came to realize that most managers would not agree to an interview without 
personally knowing me, or being introduced to me by an intermediary with whom the manager had a trusting personal relationship. As discussed earlier, such networks of relationships are common among Chinese in which intermediaries are important to establish guanxi with others (Chang \& Holt, 1991). The issue of trust is a core element in the Chinese culture, in which it possesses significant influence on relationship building and information sharing (Street \& Matelski, 2003). Therefore the first few interviews were conducted with managers with whom I had business connections, or through being introduced by an intermediary. With guanxi established during the first couple of interviews, a group of potential interviewees expanded more rapidly within this complicated network of relationships.

\section{Data analysis}

Data from the interviews were descriptive due to the complexity of this topic. I used content analysis to identify, code, and categorize the primary patterns of the interview data (Cavana, 2004). Data from all eight interviews were compared with their similarities and differences, and then categorized into sections (Eisenhardt, 1989).

Reliability for qualitative research is in many ways constrained by the fact that replications are rare (Cavana, 2004). Interview results may, thus, vary according to different researchers with different interpretations. Therefore, to make sure that the preliminary findings are as valid and reliable as possible, I took several precautions based on Miles \& Huberman (1994): 
- All findings/themes must be internally coherent.

- All findings are considered to be accurate by the interviewees.

- Continuous re-check of my interpretations and analysis of the results.

\section{Translation}

All managers interviewed were local Chinese, and as a result I had to conduct the interviews in Mandarin. I translated all of the interview scripts in as detailed a manner as possible. To confirm my translation, all translated materials were checked by a local translator. All analyses were based on the final verified translations.

\subsection{Phase 2: Qualitative Case Studies}

A qualitative methodology was also viewed as the most appropriate to employ in the second phase of this research for several reasons. First, culture compatibility is a process of human interaction, such as the sharing of values, tacit knowledge, understandings, beliefs, etc. Quantitative methods, for example statistical analysis, lack sensitivity when trying to explore and understand a process of human interaction (Yin, 1984). Since this research primarily concerns the effect of professional culture interactions between partners, I believe that qualitative methods were the most appropriate. 
Second, qualitative methods are useful in an exploratory stage with limited available preliminary knowledge, because qualitative methods have the ability to capture more information and details for the phenomena under investigation (Yin, 1994). From my knowledge, there are few published studies concerning the influence of partners' professional culture compatibility on international joint venture performance in China. Therefore, I believe that qualitative methods are most appropriate to initially explore such issues within an international joint venture.

\section{The Case Method}

A research case study is:

"an empirical inquiry that investigates a contemporary phenomenon within its real life context, especially when the boundaries between phenomenon and context are not clearly evident." (Yin, 1994: p. 13)

The case study method can be used to test, to explore, or to generate theory (Eisenhardt, 1989). For this research, the case method is used to further examine the relationships presented in the research questions because the use of case studies has been recognized by a numbers of studies as successful in the exploratory stage of research (Eisenhardt, 1989, 1991; Yin, 1994; Tellis, 1997). 
Eisenhardt (1989) stated that:

"[Case studies are] particularly well suited to new research areas or research areas for which existing theory seems inadequate. This type of work is highly complementary to incremental theory building from normal science research. The former is useful in early stages of research on a topic or when a fresh perspective is needed, while the latter is useful in later stages of knowledge." (pp. 548-549).

This is true for this study, where professional culture and its relationship with international alliance performance represent an emerging research area. Although Sirmon \& Lane (2004) have generated several propositions relating to the effect of professional culture on alliances, no empirical examinations of these have been done to date. From this, it appears appropriate to conduct case studies for this research.

Despite the benefits, there have been debates over generalization from case studies, because the samples are not enough to allow statistical analysis (Tellis, 1997). This suggests that a major limitation of case studies is their generalizability. However, Yin (1994) argued that like experiments, case studies can be generalized to theory. Like experiments, case studies can be replicated, and providing the same external conditions, the theory generated from case study analysis can be expected to hold true (Yin, 1994). However, since each case study is tied to a distinct environmental context, different studies are likely to gather a variety of different results, which together can generate richer theory about the relationships under investigation. 
Eisenhardt (1989) noted that case methods use multiple sources of information. They can create a rich and multi dimensional view of the situation. Thus, the case method is particularly useful for this research because multiple sources of data can allow the researcher to capture a range of relevant joint venture features in detail and depth.

The case method also provides the opportunity to investigate the complex and vague nature of cultural relationships to provide fresher perspectives and deeper understandings (Hanmel et al., 1993). Furthermore, the theory building process in case studies is closely tied to the evidence; thus, a chain of multiple evidences can better support the conclusion (Eisenhardt, 1989; Tellis, 1997).

Overall, the purpose of this research is to better understand the relationships between cultural differences and joint venture performance and it appears that it is most appropriate to use a set of qualitative case studies in conducting this research.

\section{Case Selection}

In this study, I have conducted case analyses of three joint ventures. The company names and individuals are disguised to ensure confidentiality. For comparative purposes, the joint ventures investigated were a mixture of Sino-Western and Sino-Eastern ventures in China. I define a Western economy as being of European ethnic origin (e.g. U.S, New Zealand, Australia, etc.), and an Eastern economy as any 
of the developed Asian countries (e.g. Japan, Korea, Taiwan, and Singapore). Analysing the influence of culture on performance in international joint ventures with partners from both diverse and similar culture backgrounds provides comparative insights offering more in-depth understandings.

I have limited the cases to manufacturing ventures only because according to Eisenhardt (1989), this approach can reduce unnecessary variations in data that may derive from analysing different industries. Furthermore, according to the China State Administration of Foreign Experts' Affairs Annual Report (2006), manufacturing ventures widely represent joint ventures operations in various industry sectors in China. They also have the longest time in operation compared to other sectors in the history of China-foreign joint ventures.

Although Eisenhardt (1989) suggested that the number of cases required for a well established research study is between four and ten, it was extremely difficult to find four to ten suitable cases to analyse. The difficulty was caused by several aspects. First, this research requires participation of both partners of a joint venture. This created barriers because either not all partners were available or not all partners were interested. Second, I had no guanxi established within manufacturing joint ventures in China. In particular, being a student from a foreign country, most partners showed no interest in participating in my research. There were also constraints on the amount of time I could spend in China and return trips to undertake additional interviews were 
not financially feasible. Finally, my connections in China were limited to the central inland provinces only. However, in China, most foreign firms and joint ventures are located in coastal cities such as Shanghai (The China State Administration of Foreign Experts' Affairs Annual Report, 2006). Different regions require a different set of social relationships (guanxi) that I didn't have, which increased the difficulties to search for potential participants in China. In addition, establishing guanxi in China requires significant time and energy, creating enormous barriers towards finding suitable participating joint ventures.

To date, there has been little, if any research on the relationship between partners' professional culture compatibility and international joint venture performance in China. Although only three joint venture cases were analysed, I believe this sample size has still captured some useful information within the available but limited time frame.

Furthermore, as Eisenhardt (1989) argued, case studies endeavour to better comprehend the phenomena under examination. It is common in case studies to select cases that represent the extreme rather than the standard because in these cases the phenomenon is clearly observable so that the process of interest is exposed. According to this, comparisons between China-Eastern and China-Western joint ventures represent the extreme in cultural differences. In addition, examining joint ventures between developed and developing economies represents another extreme 
contrast in economic/political systems, and these systems may constitute another potential influences on professional culture.

\section{Selection of Participants}

The most important criterion for selecting participant firms in this research was that both partners of the joint venture must agree to be interviewed. This is because one of the critical measurement outcomes for this research is performance, and to determine the performance of a joint venture, both partners' perspectives must be taken into account. Performance measurement will be discussed in the subsequent section. Interviews in both firms would also allow differences (such as professional cultures) to be more fully and accurately assessed.

In addition, a random selection of production related employees had to be selected for this research. According to Sirmon \& Lane (2004), the underlying reasons for the formation of alliances reflect the alliance's primary value creating activity. For example, in an R\&D alliance, the primary value creating activity would be related to innovations, scientific knowledge and technology upgrading, etc. (Sirmon \& Lane, 2004). Since this research intends to investigate manufacturing-based Sino-Foreign joint ventures, it appears logical to suggest that production is ultimately a key reason for the formation of these joint ventures. In this respect, production likely forms a primary value creating activity of the joint ventures under investigation in this research. 
In total, three joint venture cases were studied. I interviewed all partners from these three joint ventures (two from each joint venture), and also three employees. The interviews took approximately 45 minutes for each of the partners, and approximately 25 minutes for each employee. Out of the nine participants, I conducted three interviews in English and six interviews in Mandarin. I have translated all interview scripts that are in Chinese, and checked all translations with a local translator to confirm their accuracy.

\section{Measurement of international joint venture performance}

Performance has been a controversial topic in the organizational literature (Goodman \& Pennings, 1980). Such controversy resulted from the fact that performance can be measured in a variety of ways and that few indicators of performance have been widely accepted (Yan \& Gray, 1994). However, the measurement of international joint venture performance is even more problematic because "each party in the partnership is likely to adopt idiosyncratic criteria" (Yan \& Gray, 1994: p. 1482). This is to say that each partner will have idiosyncratic perspectives on performance.

International joint venture studies have been hindered with serious disagreement regarding reliability of alternative performance measures (Geringer \& Hebert, 1991). Researchers have used a range of measurements for performance. Previous studies have used a variety of cumulative performance measures such as the survival, growth, 
and profitability of international joint ventures (e.g. Killing, 1983; Li et al., 2001; Lecraw, 1984). However, such financial and aggregate measures contain serious limitations because data for these objective measurements are often unavailable or are difficult to access, particularly financial information.

Geringer \& Hebert (1991) suggested that: “financial and objective measures may fail to adequately reflect the extent an international joint venture achieved its short- and long term objectives" (p. 251). International joint ventures may be formed based upon a variety of objectives, such as technology transfer, joint research, access to materials, new markets, and economies of scale (Barkema \& Freek, 1997), and these objectives may not always be financially measurable. For example, firms entering China seeking developments in new markets or development of new technologies may not generate a financial profit for many years. In such situations, relying on financial or objective measures is unlikely to accurately measure the true performance of an international joint venture.

Because of these concerns, many studies have suggested the use of perceptual measures for performance, such as, "to what extent has the international joint venture met the expectations of your firm" (e.g. Schaan, 1988; Lee \& Beamish, 1995; Yan \& Gray, 1994). Following Schaan (1988) and Yan \& Gray (1994), I have adopted a multidimensional approach to joint venture performance incorporating the perspectives of multiple joint venture partners. In this research, I have used both 
partners' satisfaction assessment of the extent to which each had achieved its primary strategic objectives to measure the performance of the joint venture. Therefore if both partners have high satisfaction levels and achieved their primary strategic objectives for the joint venture, then the joint venture will be regarded as effective in performance. If one or both partners are not satisfied in that the joint venture had not reached its primary strategic objectives, then the joint venture will be regarded as having ineffective performance.

This measuring technique was adopted for two reasons. First, as discussed above financial and other objective data are often unavailable to investigators, thus creating difficulties and uncertainties with relying solely on this objective information to measure joint venture outcomes. Therefore, by using perceptual measurements as the principal data and archival objective information as secondary supporting data, this should allow this research to generate more reliable and comparable results.

Second, I have adopted a multidimensional and not a single perceptual approach in the measurement of joint venture performance because the compatibility of partners' employees' professional cultures and intangible complementary resources involve interactions between members of both partner firms. Thus both partners' perspectives must be taken into account to effectively comprehend the relationship between partners' professional culture, complementary intangible resources, and international joint venture performance. 


\section{Data collection}

Data for this research was collected from both interviews and archival records. According to Yin (1994) and Eisenhardt (1989), case study evidence collected and analysed from multiple sources will increase the reliability of the research.

\section{Interviews}

Interviews are one of the most important data collection methods in case studies, as Yin (1994) stressed:

"Human affairs should be reported and interpreted through the eyes of specific interviewees and well informed respondents can provide important insights into a situation." (p. 85)

This research intends to investigate human processes, such as partner employees' professional culture compatibility and the complementarity in intangible resources in international joint ventures, to create a deeper understanding of the importance of professional culture compatibility in international alliances. Thus, the use of interviews in this research is of crucial importance for gathering insights.

The primary advantage of interviews in qualitative studies is that interviews can allow researchers to focus directly on the issues under investigation (Yin, 1984). Rather than relying on large amounts of documents and archives, the researcher can directly ask 
questions to seek further understanding or related information. Interviews are the primary sources of information gathering for this research. Archival data and documents, on the other hand, are used as secondary sources of information to support interview data.

In addition, interviews can offer a richer and a more detailed description of the situation (Yin, 1984). Such details may not be visible through brief observations or the analysis of archival data. This is particularly relevant to this research, since the purpose is to understand influential relationships. Furthermore, interviews offer direct quotations from participants (Tellis, 1997). Participants' original words can most appropriately represent the real life situation under investigation. Therefore, the results should be more reliable.

\section{Research procedure}

I first contacted joint venture companies by email, attaching a research proposal explaining the goals and intended outcome of this study. I explained the need to interview both partners (or partner representatives) of the joint venture. When the first reply of interest was sent back to me, I then contacted them again by telephone to confirm participation and to arrange interview appointments.

After I had arranged for my interview times, I sent another email to the participants containing the broad topics that were to be covered, several days before the arranged 
interview sessions. This, according to Eisenhardt (1989) and Yin (1994), is a good method to reduce bias caused by poor recall of events through enabling the participants to think about the topic before having to explain it. Therefore, it helps to prevent the participants from beginning the interview uninformed and giving responses that are not representative of their perceptions on the case topic.

\section{Interview content}

I followed a pre-designed semi-structured interview protocol to conduct in-depth interviews with participants. The interview protocol was used only as guidance because I believe it is important to collect any information relevant to the case. Particularly with unexpected issues or evidences that may arise during the interview process, it is important for the researcher to be flexible during the interview process to investigate further.

The interviews addressed six broad question areas:

1. The joint venture's background, including size, time of formation, reasons for formation, products manufactured, etc.

2. The joint venture's value creating activity. Specific questions relate to the structure of the primary value creating activity, partner employees' roles in the activity, and the proportion of partner employees' involvement in the value creating activity. Also, perceptions of effectiveness of the joint venture's value creating activity (e.g. production efficiency, inventory turnover, etc.). 
3. Descriptions of the relationship between the two partner firms, especially the complementary resources each partner firm brings into the joint venture and the partner's role in the joint venture. This also includes the understanding of intangible resources each partner contributes to the joint venture and perceptions of the effectiveness in the sharing, combining and leveraging of these complementary resources.

4. Industry recognition. Specifically the length of time of each partner's employees' involvement in the industry, and their training history before and after the formation of the joint venture.

5. Employee socialization. Perceptions of the socialization and interactions between partner employees both within and outside of the working environment. Specifically, the interaction between partner employees involved in the primary value creating activity. This includes the learning and sharing of knowledge between them.

6. Finally, the performance of the joint venture. Specifically, the degree of satisfaction from each partner's perspective of whether they have achieved their intended strategic objectives from the joint venture. This also includes additional questions regarding financial performance, turnover, market share, etc. I have left these additional questions to the end of the interviews to reduce the risk that participants could become defensive about sharing information with me. 
The above question areas were developed based on the research questions. Participants for question areas that involve the understanding of partners' employees (question areas 2, 4, \& 5) will involve a random selection of employees/workers from both partners, as well as the management team of the joint venture. This will provide more accurate information, as well as different perspectives of the situation for in-depth analysis. The other question areas were directed primarily to the two partners (or their representatives) of the joint venture.

Interviews were tape recorded with no objections from participants. To assure the accuracy of the interview data, following Yan \& Gray (1994), I have also conducted member checks (Lincoln \& Guba, 1985), where the participants have verified my interview notes prior to data analysis.

\section{Data Analysis}

After participants' verified my transcripts, I conducted cross case analysis using transcripts and archival data. According to Eisenhardt (1989), cross case comparison offers two advantages. First, it can reduce the amount of data by picking out relevant themes. Especially with a limited time frame, effectiveness in data management is very important. Second, similarities from the analysis of earlier cases can rise to mind, which then can be focused more closely in the analysis of subsequent cases. 
As recommended by Eisenhardt (1989) and Miles and Huberman (1994), a common method for cross case comparison is to identify and compare case similarities and differences. As Eisenhardt (1989) suggested:

"The juxtaposition of seemingly similar cases by a researcher looking for differences can break simplistic frames. In the same way, the search for similarity in a seemingly different pair also can lead to more sophisticated understanding." (p. 541)

This research has utilized the research questions as the basis for the cross case comparison to focus on analysing important and relevant issues. I have searched for common themes, as well as differences in perspectives over the relationship between professional culture and joint venture performance.

\section{Validity and Reliability}

According to Eisenhardt (1989), one of the most important ways to enhance validity in a case study situation is the use of multiple sources of data. This study has enhanced validity by using both archival and interview evidence. Also, people representing different levels of the joint venture were interviewed. These additional multiple sources of information gathered in this research provided a rich description and deeper understanding of the situation. Another method to enhance validity is for the key participants to confirm the interview notes, and review a draft copy of the research report (Yin, 1994). 
To enhance reliability in case studies, the most important method is to minimize bias that may occur during data collection and analysis. According to Eisenhardt (1989), there are three types of bias that may occur in case studies. First, bias could occur during interviews (Eisenhardt, 1989). Such bias can happen if the participant was not reminded of the situation under investigation prior to the interviews. As discussed earlier, I have tried to minimize this type of bias by sending emails containing interview topics to the participant several days before the interview session. Interview bias can also occur if the interviewer represents higher authority or power over the participant (Eisenhardt, 1989). If this happens, especially in a hierarchical society as China, the participant may have concerns or fears with presenting their true perceptions of the situation. However, this type of bias is very unlikely to happen in this research because I'm only an overseas student.

Bias can also occur during data analysis, where the investigator can "leap to conclusions based on limited data... overly influenced by the vividness or by more elite respondents... or they sometimes inadvertently drop disconfirming evidence." (Eisenhardt, 1989: p. 540). In this situation, cross case comparisons can minimize such bias, as Eisenhardt (1989) noted that: "the result of these forced comparisons can create new categories and concepts which the investigator did not anticipate" (p. 541). This indicates that the investigator does not simplistically search only for evidence matching the initial research questions. 


\section{Results and Findings: Phase 1}

All eight managers were interviewed, and showed interest in this topic. I have labelled the participating managers to assist with presenting data: Hospitality manager A, B, C and D, Manufacturing manager A and B, IT manager A and B.

In general, the managers consider this research to be worthwhile. The managers believe that the understanding of Chinese national culture has great potential to assist foreign investments to achieve better performance.

Although the managers were not currently employed in joint venture firms, most of them still told stories about how some foreign partners in their industry have failed due to the lack of understanding of the Chinese environment, and where others have succeeded in business by adapting towards the Chinese system. When we were discussing Sino-Western joint ventures, general opinions were that culture compatibility is the most crucial factor for success, and that Western partners (regardless of how large or financially capable they are) must adapt to the Chinese business system. As Hospitality manager B said:

"If you come to China and form a venture with me, we will learn and share much knowledge among each other. However, the running of the venture must adapt to the big environment in China to survive, therefore you being the Western 
counterpart must understand Chinese culture to also adjust in this changing environment. For example, foreign partners must learn and adapt to the 'proper' use of guanxi in China."

Based on the manager's perspectives, this chapter will first present findings regarding the influence of the three schools of thought (Confucianism, Daoism, and Buddhism) on the contemporary business environment in China. This chapter will then present findings on the influence of different national culture factors on professional cultures in China.

\subsection{The Chinese culture and business environment}

The Chinese business environment is changing rapidly due to the country's rapid economic development. It is in many ways moving towards a global standard of market economy. However, China is still currently a socialist country and such a shift towards capitalism will take a considerable amount of time. All managers believe that no matter how much China changes, in terms of 'how to conduct business' in China, this will still be dependent on its key cultural characteristics. Contemporary Chinese culture has been shaped by a long history. For example, Hospitality manager C said, 
"We have five thousand years of history, and our history has provided many examples of great successes and failures. These lessons were passed on from generation to generation till the present day. It is in our nature to follow the thinking of our ancestors, to learn from both their accomplishments and mistakes. These lessons have influenced how we perceive the world, and how we conduct businesses."

From the interviews, the managers themselves have provided some major cultual characteristics. On revisiting them, they perceive as valid and reliable and shape the contemporary business environment in China.

The table below presents, national cultural factors influencing contemporary Chinese business environment. The contents of this table are not in a ranking order. This table will be discussed in detail in subsequent paragraphs. 


\section{Table 2:}

Framework of influential Chinese cultural characteristics in the contemporary business environment

\begin{tabular}{|l|l|}
\hline Influential Cultural Characteristics in & Philosophical Origin \\
\hline 1. Guanxi & \\
\hline 2. Concept of Face & Confucianism \\
\hline 3. Respect for Elders & Confucianism \\
\hline 4. Collective harmony/Harmony with the universe & Daoism \\
\hline 5. Avoidance of Direct Confrontation or conflict & Daoism \\
\hline 6. Resistance to Change & Confucianism \\
\hline 7. Uncertainty avoidance & Daoism \\
\hline
\end{tabular}

The table clearly illustrates the influential cultural characteristics and their philosophical background. It is interesting to discover that all interviewed managers feel that Buddhist philosophies had only minor influences on the contemporary Chinese business environment. All managers suggest that Buddhism primarily concerns a person's inner spiritual well-being, and most people treat Buddhism as a 
religion rather than a philosophy. It has low or no impact on people's actions or reactions towards the business environment.

The above cultural characteristics influence the contemporary business environment in a variety of ways. Below, I will discuss each influential cultural characteristic individually.

\section{Guanxi}

All managers believe that the most important feature to understand when conducting businesses in China is the use of guanxi, 'the Chinese way' to communicate. The term 'guanxi' represents a network of mutual obligations and understandings, and such obligations contribute towards long term, secure, and trustworthy business and social relationships (Luo, 1997; Street \& Matelski, 2003; Abdahlla, 2002). Manufacturing manager A said:

"Without guanxi, you will go nowhere. Everywhere you see, anything you want to do, even the smallest things in life (e.g. such as buying quality vegetables) you will need guanxi to make the process smoother. In our business situations, we need guanxi not only to sell our products, but also to buy quality raw materials. It is this big system of relationship building which we cannot escape from it." 
Manufacturing manager B suggested:

“guanxi exists because of a 'courtesy - demand - reciprocate' reality in the society. Say if we sell some good products to a specific party at extremely low prices (or even sell it at a loss) based on the guanxi we have, then we will know for certain that some time in the near future we will be able to receive some form of benefit from that party. These kinds of relationships are extremely helpful at times, such as when problems arise or we need help from others. We see the establishment of guanxi as a social investment."

As discussed earlier, although 'guanxi' originated from Confucianism, the current use (e.g. as a social investment or a tool) is not necessarily a Confucian ideal (Chang \& Holt, 1991). When I asked the managers why guanxi has become so important in China, they generally suggested that it was caused by history. Hospitality manager C said:

"There have always been laws, regulations, and policies throughout Chinese history; however, history also showed us that these systems of control had weak influences on people's behaviors. Behaviors were controlled instead by ancient philosophies, and thus consequently resulted in less respect for social laws and regulations. This then provided a foundation for the use of guanxi in a variety of ways. For example, bribery is a common form of the use of guanxi throughout 
Chinese history, and history has showed many examples of how people break laws or get away with unlawful activities by using this form of guanxi."

Hospitality manager A said:

"Guanxi is related with power... When we say 'someone has a lot of powerful guanxi', we are indicating that this person has much social power. Thus, the power of guanxi cannot be doubted, especially when such power still exists in the present day."

This finding is consistent with studies discussed in the previous chapter suggesting that guanxi is the unofficial law in Chinese societies, where people rely on relationships with people in power to carry out tasks (e.g. Chen, 1995).

The managers have suggested that guanxi could be a study by itself, for example, Hospitality manager D said:

"Some people have spent their entire lives trying to fully comprehend it, and it is very difficult to learn. It is a social book" 
She continued:

"It is difficult enough for Chinese people themselves trying to 'play the game', not mentioning foreigners."

As a result, the managers believe that trying to explain guanxi is extremely difficult, and to understand how to use it in a Chinese surrounding is even more complicated. If foreigners want to learn it, they must personally experience it first.

\section{The Concept of Face}

This concept is deeply interrelated with guanxi. Guanxi involves an exchange of face, where people give face to someone to increase their social prominence (Huang, 2004; Chen, 1995; abdahlla, 2002).

IT manager A said:

"It is really similar to guanxi, you need to have 'face' so people can respect you... Face is a measurement of success. It is also an expectation from family members, for example, your parents, wife, and even your children. If you have face in society, you bring face to them, and people will respect them as well." 
Manufacturing Manager A said:

"With face, people will think you are reliable and trustworthy. The difference between guanxi and face is that guanxi represents social relationships and mutual obligations with people that you can do either good things or bad things with. Face on the other hand will mostly be given or achieved through positive things you do."

The concept of face contributes to the contemporary business environment in the same way as guanxi does, where people need to have face in the society, to establish more guanxi to increase their social power, or to ask for favors or help from others (Scarborough, 1998; Chen, 1995). For example, Hospitality manager A said:

"Face will give you the chance to meet and establish guanxi with more 'powerful' people that can help and guide you throughout your career."

Therefore, as the managers suggested, to conduct any business in China without guanxi or face will incur numerous constraints throughout one's business development process. 
Respect for Elders

This culture character has contributed to a strict hierarchical system in China (Redding \& Wong, 1986). Respect for elders is a moral standard for every Chinese. Based on the teachings of Confucius, Chinese people have been raised to obey their parents, older brothers/sisters, teachers and leaders (Scarborough, 1998; Abdallah, 2002). For example: Hospitality manager B said:

"Respect for elders is very important in China. If you show good respect for elders, not only will you 'climb' faster (in work places), but also you will earn face and respect from people. People who disrespect elders will have no face in society."

Manufacturing manager A said:

"We have been taught from youth that individualism is not healthy. There is a famous proverb in China, saying 'if you don't listen to the elders, you will fail'."

This also overlaps with collective/universal harmony in Daoism, which I will discuss later.

The general assumption is that elders have more experiences in life; therefore they can point you in the right direction to avoid mistakes in life. This consequently 
resulted in a system of hierarchy, from family, to workplace, to the entire society. It is interesting that IT manager B said:

"When I was younger, I strictly obeyed what my father said. For example, I wanted to study art when I was in university, but my father pushed me to study computer because he believed that a degree in computing would be easier to find jobs. I'm not sure if he is correct or incorrect, but the fact shows that I'm sitting here in a stable work position because I listened to his advice."

He continued:

"This is Chinese culture. In my situation for example, I follow my director at work, and follow my father at home. When I get old enough or reaches a high social position, then I would expect others to follow me.”

Many researchers argue that one of the important influential cultural characteristics of the Chinese business environment is 'respect for authority' (e.g. Nevis, 1983; Huang \& Cullen, 2001; Child, 1995). However, some managers believe that 'respect for authority' is only an illusion. Hospitality manager $\mathrm{C}$ said:

"If everybody respected authority, then the current meaning of guanxi would not exist. Many use guanxi to seek a passage through loopholes in laws and regulations. This shows disrespect to national authority." 
While the findings from this study suggest that 'respect for elders' is still a major culture characteristic and exists in contemporary Chinese minds, 'respect for authorities' appears to be a false or only a surface appearance. Past studies may not have identified differences between these two similar culture characteristics, or simply assumed that they are the same. On the other hand, studies e.g. Chen (1995) noted that Chinese people use guanxi to carry out tasks as opposed to using legal systems as in the West, and in many ways this reveals disrespect for laws and regulations. This might be caused by frequent interactions with individualistic Western cultures. These interactions will have considerable impact on younger individuals in China especially, who are more accepting of new cultures. The influence of interactions with the West will be discussed in later sections.

Harmony with the Universe, Avoidance of Direct Confrontation, Resistance to Change, and Uncertainty Avoidance

The last four cultural characteristics originated from Daoism. These characteristics have influenced the contemporary Chinese business environment by the way people perceive reality and the universe. The majority of authors (e.g. Abdahlla, 2002; Street and Matelski, 2003; Chang \& Holt, 1991; Luo, 1997; Chen, 1995; Redding \& Wong, 1986) believe the Chinese business environment and managerial behaviors are based on the teachings of Confucius. However, most of the managers expressed alternative opinions. Manufacturing manager A said: 
"Confucian principles influenced our actions in life, and Dao influenced our reactions to life. Everything appears to be under the influence of Confucianism, because it does influence our business systems. However, the influence of Daoism is more than appearance. It influences how we react to business issues. For example, the way we react to problems or business contingencies is based on Dao instead of Confucian principles."

The managers believe that the influence of Daoism is actually as great, or even more important, than Confucianism in its contribution to the contemporary Chinese mind.

Dao emphasizes the equilibrium between a human and his surrounding nature to develop a sense of harmony (Chan, 1967). With this harmony, one should not force or deny nature (Thompson, 1975). Based on Daoist principles, for example, Hospitality manager A said:

"If issue arises, it will and should resolve naturally. It is just a matter of time... A good example of Dao in the business world is that if person A was to ask person B for a favor, person B would never refuse person A even if he can not or would not do the favor. This problem will be naturally resolved when person A realizes over some time that person B tries to keep distance or refuses to discuss about the favor... you see, Chinese people don't like to be straight with you. They expect you to understand them through their actions rather than words." 
Hospitality manager B had similar opinions:

'People in China like to say 'half a sentence.' They expect you to understand what the other half means. Particularly with government departments, everybody has to try to understand and study what's in your leader's head. You will be considered immature if you can not master that."

Both Confucianism and Daoism emphasize collective harmony, but the managers argue that collective harmony first originated from Daoism. Daoism influenced the Chinese culture to have a 'being orientation', as opposed to Western culture's 'doing orientation' (Chan, 1967). To maintain this collective harmony, Chinese people are unlikely to consider direct confrontations towards issues. Instead the Chinese people will search for alternatives in a conflicting situation. Because of this collective harmony orientation, people tend to think that direct confrontation is a destructive problem solving method that can cause series of unhappiness. Instead, the Chinese people choose middle positions that will satisfy or partially satisfy all conflicting members. This has led to another cultural characteristic of Avoidance of Direct Confrontation. Manufacturing manager B said:

"No Chinese (with some decent education) will ever choose direct confrontation as their problem solving method. Harmony and politeness is always on the appearance, although things can get pretty ugly below the surface, but that would be another 
story. People will always approach problems indirectly, and the most common method is to find a middle ground or an intermediary through guanxi."

And IT manager B said:

"If I approach someone directly with a problem in this company (unless the problem is urgent or very serious), then people would think I have no 'skills' with handling issues. Another word, people will think I'm rude and uneducated."

Cultural characteristics of resistance to change and uncertainty avoidance originated from historical habits of Chinese people. The philosophical background of these characteristics was from Daoism. Chinese civilization began from agricultural roots, where people relied on the natural environment and agriculture to survive (Scarborough, 1998). Based on Dao, people resisted to change environments and to face uncertainties in order to develop this equilibrium with its existing environment (Chan, 1967). Unnecessary changes were considered unhealthy. These beliefs have passed on to modern environments, and are still affecting people's attitude, especially with the elder ones. Hospitality manager D gave an example:

"Even today, the elder generations in our society are extremely resistant to any changes. This is very different to foreigners. When foreigners retire, they will probably travel around and see the world. But in China, when people retire, they will go nowhere. Staying in one place can provide them with a sense of 'safety' 
because they are familiar with the environment. They are not keen to experience other lifestyles or to explore other environments. They will just do whatever they do everyday until they die."

Manufacturing manager B said:

"I have a resistance to change myself. Although I wish to expand my career and see the world, but I prefer to live in the same environment and industry. I believe in most Chinese people's mind, stability is better than anything. That's why many parents want their children to be public servants, because a public servant represents an 'iron rice bowl' (guaranteed income). So, to avoid uncertainty means to avoid instability."

However, as suggested by the managers, these cultural characteristics (resistance to change and uncertainty) have a lesser influence on the younger generation due to more frequent interactions with the West. In addition, the global environment is constantly changing with rapid economic development. Therefore, to survive in modern days, people must be willing to change and to face uncertainties. IT manager B suggested that:

"I'm not sure about others, but because I'm not in a very stable industry, and I see people, particularly young people, adapting to changes very quickly, so I believe that perhaps survival for many industries today is to face and explore uncertainty 
rather than avoiding it. But on the other hand, if I'm in my father's shoes, I would think differently."

Most managers still think that resistance to change and uncertainty is still ingrained in many Chinese people. Hospitality manager A indicated that:

"If people have a choice, then most will probably choose to stay in one place doing the same job forever."

\subsection{Professional culture in China}

In general, most managers believe that professional cultures do exist in their industry, and support Sirmon \& Lane's (2004) propositions regarding the importance of professional culture, and that it is shaped by national culture.

"The professional culture concept makes sense. I think it is important for foreigners to work out how Chinese national culture reflects on domestic professions... One situation I can think of that may differ to Western companies is that general managers in China, even with small companies, don't deal with the day to day running of the business. All they do everyday is visit people, eat with people, play with people, etc. They often don't even show up in the 
company. It is the deputy or department managers that run the business. This situation in China is particularly common because of the enormous time and energy required in the China market to establish and maintain guanxi. And as a result, many company managers in China have much better skills with people and communication, as opposed to management and organizational skills." (Hospitality Manager D)

IT manager B said:

"I've never been involved with forming alliances with foreigners, but if I am going to one day, I will try to understand working habits from the other party. Differences in people's work habits, I believe, represent differences in their professional culture. So if foreigners enter China without knowledge in how Chinese people work, then I believe they will come across many troubles... I think for foreigners, understanding Chinese culture is one thing, but understanding the outcomes caused by Chinese culture is more important."

On the contrary, IT manager A argued that professional culture doesn't exist in his industry. IT manager A said:

"Understandings of different professions are the same worldwide, for example, a software designer. However, software designers differ by the countries they live in. Different countries provide them with different work habits, attitudes and 
perceptions of their profession, and problem solving techniques, etc. Although you can argue that this is the difference in professional culture, I believe that the difference is actually in national culture. Therefore in my view, as long as we are not talking about a profession that is only for a specific country, then I believe there is no such thing as a professional culture."

Hospitality manager $\mathrm{C}$ had a similar opinion:

"I think what you are saying is a little too theoretical. I think in practice you can not, in general, separate professional culture and national culture. For example, national culture characteristics such as face, avoiding upfront arguments, etc. This will apply to any profession in the country."

When I asked the managers to try to identify professional culture characteristics in China, the general response was that it is much more difficult to identify as opposed to national culture. Thir responses suggested that professional cultures are not distinct. They are interrelated with the national culture and other country factors.

"The way you conduct your professional activity is obviously heavily influenced by your national culture; however, it is not possible to generalize professional culture characteristics in China unless you look specifically into one or a few professions, and then you may find some general professional culture 
characteristics that would apply to those professions." (Manufacturing Manager B)

Hospitality manager A suggested that:

"There are too many professions in China, and you can probably identify different characteristics for different professions. However, going back one step, if you have a look at any kind of professional habits or attitudes, you can probably easily trace its cultural origin. For example, you may find people in the creative industries in China are less creative than professionals from Western countries. This may result from the nature of education in the Chinese society where it is not healthy for young generations to stand out and think independently. Therefore in my opinion, professional cultures exist in China, it is important, but it is not distinct from national culture or other country factors."

With regards to the construct of professional culture in general, the managers believe that a professional culture can result from a variety of factors, not limited to only national culture. The general response to Sirmon \& Lane's (2004) model of 'cultural differences and international alliance performance' was that this model appears to be too simplistic or too idealistic for China's situation. From the managers' perspective, they believe that it is unrealistic to suggest that professional culture is derived solely from national culture (national culture being the only factor Sirmon \& Lane 
mentioned as the driver of professional culture). For example, Manufacturing manager A said that:

"China is a special economy at a transition stage. Because of this, professional values in China may be influenced by a variety of factors. For example, the acceptance of Western ideology, economic developments, all can change and reshape professional understandings in China. I do not believe that professional culture is shaped by only national culture."

According to the managers, national culture, the nation's economic development status, industry understanding, and the degree of interactions with foreign countries were all seen as contributing factors towards one's professional culture. Below I present the findings in detail.

National Culture: According to the managers, the influence of national culture on professional culture is significant. All of the identified national cultural characteristics, for example guanxi or the avoidance of direct confrontation, apply to any profession in China. As noted by Hospitality manager D:

"As long as you are in the Chinese environment, regardless of what profession you are in, concepts such as guanxi and face are inevitable."

She continued, 
"If we join, for example, our sales force with a Western firm, I believe our attitude and techniques in sales will be extremely different to our Western counterparts. Such as the way we develop sales routines, strategic methodologies, problem solving techniques, etc. This shows significant differences in professional understandings. But these professional understandings, like I said before, it's a reflex of China's national culture and such reflexes will apply in general to any profession in China."

Economic Development: One important contributing factor suggested by most managers was the degree of economic development. This factor may only be important in developing economies where economic development often represents instability, as opposed to developed economies. This finding is consistent with past studies suggesting that economic development has considerable influences on businesses, especially in developing economies (e.g. Lee \& Beamish, 1995; Li et al., 2001; Child \& Tsui, 2001). IT manager B said:

"A nation's development process is often unstable. This means that the nation will focus on developing different industry areas according to different stages of the development. It is understandable that you cannot develop everything simultaneously. But because of this constant change in focus, it can greatly influence people's perception over the industry they work in - thus, also influencing professional understandings within that industry." 
He continued:

"For example, the IT industry used to be less developed than the manufacturing industry. Therefore, our industry was considered less important than the manufacturing industry. This 'lesser importance' also extended to all the people working in our industry regardless of what they do. Later, with the emphasis on the development of our industry, people began to realize the importance of our work. This awareness has changed much in our views and attitudes towards our profession and how we should develop. This has contributed heavily to professional understandings within our industry. Take the profession of being a scientist for example: attitudes, habits and values of scientists in our industry will differ greatly from scientists in a lesser-developed industry.”

\section{Hospitality manager A said:}

"Because we are in a service industry, therefore values change in our industry as the country develops. The more our country develops, the more 'fussy' the service standards must be. Therefore we are forced to continuously renew our understandings and values in the word 'service', so we will not be left behind in this competitive market."

Interactions with foreign countries: National economic development also interconnects with the degree of interactions that China has with foreign countries. 
Interaction between countries can provide learning environments for their members to exchange knowledge among each other. Manufacturing manager A said:

"Many companies are now using foreign educated Chinese to run their businesses. This is caused by the need to interact with international markets. Sometimes we have to inject 'new blood' in our systems to suit the international market, where traditional ideology from our culture sometimes make us too conservative. With fierce competition in the market, particularly in the manufacturing industry where profit margins are so low, we need to think outside of the Chinese borders. And I believe this has consequently changed our business values."

IT manager A said:

"Our company, and probably most companies in this industry I believe, is heavily involved with the outside world, and it is very important for our development to suit the international market. I believe how we work is definitely influenced by the interactions we have with our clients overseas."

Hospitality manager B said:

"Perspectives and values of many professions have changed in recent years due to constant interactions with the West. For example: doctors, lawyers, athletes, etc. All of these professions were viewed in China as normal professions under 
the influence of communism, where in the West, these professions are highly paid and respected. When China's economic reforms began, interactions between Western countries and us became frequent. Therefore, under the continuous exchange and influence in Western ideologies, these professions are now also treated as high-class and highly respectable professions."

Industry recognition: During the interviews, I found that interactions between countries also influenced industry recognition, and that industry recognition was perceived by the managers as another contributing factor shaping professional cultures in China. For example:

Hospitality manager B continued:

"The recognition of our industry was also partly influenced by the interactions with Western countries. Foreign investments brought international service standards and activities to our industry. From these interactions, we understood, for example, what an international hotel standard is. These interactions raised our industry onto a new platform, and with these changes, it has also influenced changes in consumer taste. It is like a chain reaction, and every movement within this chain will place significant influence on perceptions and values over related professions." 
Hospitality managers A \& D had similar opinions:

"The service industry has changed significantly due to fast economic development. These changes in our industry changed the way we serve people. If we do not change, then we are no longer competitive." (Hospitality manager D)

"We have to make sure all our staff members are up to standard, to become real service professionals in the international market, because this is the new standard for our industry.” (Hospitality manager A)

Manufacturing Manager B said:

"I believe the industry can also shape professional cultures because you often find that people in the same industry tend to have similar work values. Because of heavy competition, therefore companies within the same industry will try to copy one another. For example, if he signs a contract to manufacture bags for an American company, I'll also try to find a contract job to manufacture something for the U.S market. Because of this, people in the industry would be similar in areas such as management skills, negotiation techniques, problem solving methods, development directions etc."

This is consistent with Kedia et al.'s (1992) study, as illustrated in Sirmon \& Lane (2004), where they found a positive relationship for R\&D innovations with the 
research and academic industry understandings (e.g. related with the lower power distances in the research industry).

In general, the managers noted that professional cultures are related to four factors: national culture, economic development, interactions with foreign countries, and industry recognition. The factors affecting professional cultures in China, as suggested by the managers, are more numerous and complex than the relationship illustrated by Sirmon \& Lane's (2004) model. 


\section{Results and Findings: Phase 2}

Three Sino-Foreign joint ventures agreed to take part in the interviews. Two are Eastern-Western joint ventures, and one is an Eastern-Eastern joint venture. This difference in partners allows for some comparison between joint ventures from similar cultural backgrounds and joint ventures from more diverse cultural backgrounds.

Under the confidentiality agreement I cannot disclose any company or participant names. Therefore I have coded the joint ventures as A, B, and C. Venture A is a Sino-Australian joint venture manufacturing bio-chemical sprays; venture $\mathrm{B}$ is a Sino-American joint venture manufacturing agricultural chemicals, and venture $\mathrm{C}$ is a Sino-Taiwanese joint venture manufacturing electronics (Table 3). 
Table 3

Summary of the joint venture profiles

\begin{tabular}{|c|c|c|c|}
\hline & Venture A & Venture B & Venture C \\
\hline $\begin{array}{l}\text { Manufacturing } \\
\text { product }\end{array}$ & Bio-Chemicals & Agri-Chemicals & $\begin{array}{l}\text { Household } \\
\text { Electronics }\end{array}$ \\
\hline Year of formation & 2000 & 1994 & 1997 \\
\hline $\begin{array}{l}\text { Number of } \\
\text { employees }\end{array}$ & 130 & 1600 & 700 \\
\hline Product market & $\begin{array}{l}\text { Mainly domestic, } \\
\text { small amount for } \\
\text { foreign market }\end{array}$ & $\begin{array}{l}50 \% \text { domestic and } \\
50 \% \text { export }\end{array}$ & $\begin{array}{l}\text { Mainly domestic, } \\
\text { small amount for } \\
\text { foreign market }\end{array}$ \\
\hline $\begin{array}{l}\text { Foreign partner } \\
\text { key resources }\end{array}$ & $\begin{array}{l}\text { Manufacturing } \\
\text { technology, } \\
\text { knowledge in } \\
\text { production/quality } \\
\text { control, chemical } \\
\text { recipe, foreign } \\
\text { market access }\end{array}$ & $\begin{array}{l}\text { Manufacturing } \\
\text { technology, R\&D, } \\
\text { knowledge in } \\
\text { production/foreign } \\
\text { market, chemical } \\
\text { recipe, foreign } \\
\text { investments, } \\
\text { foreign market } \\
\text { access }\end{array}$ & $\begin{array}{l}\text { Production } \\
\text { knowledge, } \\
\text { manufacturing } \\
\text { technology, } \\
\text { experiences in } \\
\text { international quality } \\
\text { standards, finance, } \\
\text { foreign market access }\end{array}$ \\
\hline $\begin{array}{l}\text { China partner } \\
\text { resource }\end{array}$ & $\begin{array}{l}\text { Finance, local } \\
\text { market knowledge } \\
\text { and access, cheap } \\
\text { labour }\end{array}$ & $\begin{array}{l}\text { Local market } \\
\text { knowledge and } \\
\text { access, cheap } \\
\text { labour, existing } \\
\text { production line }\end{array}$ & $\begin{array}{l}\text { Finance, local market } \\
\text { knowledge and } \\
\text { access, cheap labour }\end{array}$ \\
\hline $\begin{array}{l}\text { Joint venture's } \\
\text { primary value } \\
\text { creating activity }\end{array}$ & Joint production & $\begin{array}{l}\text { Joint production \& } \\
\text { marketing }\end{array}$ & Joint production \\
\hline $\begin{array}{l}\text { Foreign partner's } \\
\text { primary strategic } \\
\text { objectives }\end{array}$ & $\begin{array}{l}\text { Profit, business } \\
\text { growth }\end{array}$ & $\begin{array}{l}\text { Profit, business } \\
\text { expansion, learn } \\
\text { how to do business } \\
\text { in China, }\end{array}$ & $\begin{array}{l}\text { Low cost, profit, } \\
\text { market share, } \\
\text { business growth, }\end{array}$ \\
\hline $\begin{array}{l}\text { Foreign partner's } \\
\text { other strategic } \\
\text { objectives }\end{array}$ & $\begin{array}{l}\text { Low cost, large } \\
\text { scale } \\
\text { manufacturing }\end{array}$ & $\begin{array}{l}\text { Low cost, market } \\
\text { share }\end{array}$ & \\
\hline $\begin{array}{l}\text { China partner's } \\
\text { primary strategic } \\
\text { objectives }\end{array}$ & $\begin{array}{l}\text { Profit, sourcing } \\
\text { new technology, } \\
\text { business growth }\end{array}$ & $\begin{array}{l}\text { New technology, } \\
\text { foreign } \\
\text { investments, export }\end{array}$ & $\begin{array}{l}\text { Foreign investment, } \\
\text { profit }\end{array}$ \\
\hline $\begin{array}{l}\text { China partner's } \\
\text { other strategic } \\
\text { objectives }\end{array}$ & $\begin{array}{l}\text { Foreign expertise, } \\
\text { technical } \\
\text { knowledge, export }\end{array}$ & $\begin{array}{l}\text { Profit, foreign } \\
\text { expertise, business } \\
\text { growths, foreign } \\
\text { R\&D }\end{array}$ & $\begin{array}{l}\text { New technology, } \\
\text { foreign expertise and } \\
\text { knowledge, export, } \\
\text { business growth }\end{array}$ \\
\hline
\end{tabular}


This research found that in all three cases, foreign partners provide manufacturing technology, knowledge and skills, and their Chinese counterparts provide labor and access to local markets.

Findings from this research are displayed based on the relationships and factors derived from the research questions.

\subsection{Relationship between related complementary resources and the value} creating activity

As reviewed in Chapter 2, according to Sirmon \& Lane's (2004) proposition:

“The complementarity of partners' resources positively affects alliance performance only when those resources are related to the primary value-creating activities of the international alliance, and when the employees involved in those activities interact effectively.” (p. 309)

According to Sirmon \& Lane's (2004) argument, the presence of partners' complementary resources alone does not always provide positive outcomes. Alliances require an effective sharing and combining of partners' resources that is related to the primary value creating activity in order to produce positive outcomes. 
The findings support the above relationship between partners' complementary resources and primary value creating activity, however, the findings suggest that all resources that partners bring into the joint venture are either directly or indirectly related to the venture's primary value creating activity.

Most participants have suggested that it is crucial for an effective pooling together of resources in their joint ventures to produce good results. The following quotes provide some evidence:

"Successful sharing of resources results in stable production.... it is very important for us because if our sharing isn't effective, that could leave us with products not suitable for the local market, or products not up to standard. This then can cause ongoing problems with the running of our production line." (Foreign partner from venture A)

"Of course, such co-operation of resources determines the future of this joint venture. If our partners don't have resources that complement ours, then I believe there is no need for this joint venture." (Chinese partner from venture A)

"Sharing of resources promotes better business in our venture. Effective sharing of resources such as knowledge and skills also helps with communication between the two partners and the partner employees; this in turn contributes to the smooth running of our production." (Chinese partner from venture C) 
"We are more effective in what we do now because we can communicate better. They (their foreign counterpart) taught us many new skills when using their machines, and we taught them many of our methods as well. The working environment is better than when we first started." (Chinese employee from venture B)

There are few participants suggesting that the smooth running of a joint venture's primary value creating activity alone does not always lead to positive outcomes. They have suggested that there are often differences between a good outcome for the joint venture and a good outcome for the partners. I will discuss this later in the performance section.

In probing further as to whether only the complementarity of resources related to the primary value creating activity can provide positive outcomes, some participants were confused over the meaning of 'complementary resource' and 'related'. In particular, the Chinese partner from venture B said:

"Every resource we bring into the joint venture is related to the primary value creating activity, or else the resources have no value to the joint venture in the first place... For example, although our primary value creating activity is the manufacturing of agri-chemicals, this doesn't necessarily mean that only knowledge and skills related to manufacturing is so-called 'related resource'. 
Anything from market knowledge/access to guanxi techniques all have indirect effects over the smooth running of our business."

Others suggested:

"What is related? ... Some resources, for example, sales techniques, have no influence on how we produce, but sales is one of the most important parts in this value chain; although not production related, it is still very important. In my opinion, all resources, regardless of production relatedness, must be utilized to make a joint venture, like ours, successful... Like I said, if sales is not good, even with excellent running in production, it is still useless." (Chinese partner from venture C)

Overall, it is difficult for the researcher and the interviewees to identify resources contributed that were not seen as complementary or not value-creating when unrelated to the primary activities of the joint venture.

This research also found that the effective sharing of partner resources does not happen in a short time, especially with intangible resources such as knowledge and skills. In particular, the foreign partner employees from ventures A and B find that the Chinese working environment differs in many ways from their home environments. They believe the main obstacle for an effective sharing of knowledge is the 
communication with their Chinese colleagues. A foreign employee from venture B stated that:

"Language is a barrier to every one of us. Language difficulties hinder accurate transfer of knowledge, regardless of how good your translator is."

"I sometimes feel disabled because I need to rely on my translator every minute of the communication with our partners. Often immediate verbal translation can cause errors and misunderstandings ... this often is very time and energy consuming." (Chinese partner from venture B)

The foreign partners from ventures $\mathrm{A}$ and $\mathrm{B}$ have suggested that communication precision is very important for them, particularly with manufacturing chemicals. It took some time to develop an understanding between the employees from diverse cultural and language environments. This transitional period can negatively influence production (the primary value creating activity), in which the joint venture managers have to spend significant time and energy to establish a shared basis of understanding rather than focusing on the running of the primary value creating activity. The foreign partner from venture A said:

"Production wasn't always smooth. Particularly during the first couple of years, we had serious communication issues with our Chinese colleagues ... it took a while to teach local workers and the so called 'professionals'. Communication is much 
better today... I'm not saying that we don't have issues. I'm saying that we are making progress."

"It took quite some time to comprehend the Chinese system ... We have experienced very difficult times in the past, as a result of communication errors. Now is much more stabilized.” (Foreign partner from venture B)

In contrast to the difficulties noted above, no issues have been identified for the complementarity of tangible resources such as finance and equipment. It is rather the transfer of knowledge and skills between partners and partner employees that appears most problematic, particularly during the initial stages of the joint venture. This suggests that the sharing of intangible resources is of significant importance, as the foreign partner in venture A suggested:

"We are lucky to not come across problems with agreement violations or copyright issues, as they are so common in China. Long before we came here, we were told these problems are pretty bad in China. I believe we are very fortunate to have honest partners... Tangible resources can cause problems if not shared efficiently, but in saying that, those problems are most likely to occur among dishonest agreements." 


\subsection{Partner Employees' professional culture compatibility}

The following comment made by the Chinese partner from venture A provided a good metaphor for professional culture in joint ventures:

"Like drawing something on a blank paper, you can start fresh. But for a paper with existing drawings, you must rub it off first before drawing new things on it. It is impossible for most employees to 'rub their drawings off' completely and design new ones to suit the environment, but it is possible to have strong overlaps. This is what joint ventures must work on... and yes, this overlap image is very important to establish good sharing of resources between partners."

Unfortunately this 'overlap image' does not come easy. The findings here suggest that it is very time consuming to make partner employees' professional culture compatible.

"Of course, it's like asking an experienced Chinese chef to cook Western food. No matter how hard he tries, the food will still taste Chinese ... This applies to what we do as well - no matter how much you want to change to new environments, you still tend to often do things your old way." (Chinese partner from venture A)

"Everybody takes time to change to new environments including myself.

Personally, I find it difficult to change my way of conducting business, for 
example, we have board meetings once or twice every couple of weeks, and during the meeting if I think something is not good, then I will say 'that's no good'. But often the Chinese think what I say is quite disturbing. On the other hand, if they wish to comment on issues, then they will say something like 'it's good, but by doing this, it will be better'.” (Foreign partner from venture B)

This last quote supports some of the findings from phase1, that Chinese people have distinctive methods in putting their opinions forward and resolving problem. Thus, consistent with other studies, for example Chan (1967) and Scarborough (1997), this provides an example of Daoism applied in the Chinese business environment (avoiding direct confrontations) and may also be related to the culture characteristic of 'face'.

The foreign partner from venture B continued:

"We bring new concepts, new technologies for agricultural chemicals into China, and we require workers to work according to our guidelines. Otherwise transferring of knowledge becomes useless, and also meaningless ... On the other hand, for us to run the show in China we also need to change our thinking in many ways ... everyone has to make sacrifices. Unfortunately, nobody can change in a day. It took us some time to understand each other well, particularly for people like our senior engineers." 
As discussed by partners from ventures A and B in particularly, joint ventures require a transitional period to establish understandings between both partners and their employees. This transitional period represented high cost and low outcomes for all three joint venture cases.

The foreign partner of venture B stated:

"There was a time when I had no faith in this project because communication was very bad between us and the Chinese ... production was in a mess, cost was higher than expected, and we even had a serious work injury because they didn't fully understand our safety procedures."

Professional culture constitutes a balance of professional values and practices (Karahanna et al., 2005). In all three cases, participants believe that time can change the partner's professional and organizational practices to be compatible. However, fundamental values, such as national cultural characteristics that relate and influence their professions are difficult to change, and these values are nation specific. This supports a number of studies (Karahanna et al., 2005; Erez \& Earley, 1993). For example, the Chinese partner from venture B said:

"We are willing to learn from them. They have very high technologies and distinct management skills that can help business growth. But sometimes their methods of doing things are contradictory to ours. For example, the Americans are sometimes too straightforward, which in our culture this can cause bad image 
and bad business. Also at early stages they don't quite understand the need to invest a lot of company money inviting government officials for dinners and other activities to establish guanxi ... we find it hard to change everything to suit them."

"We struggled a little with our foreign partners in the beginning because both parties lack knowledge in each other's culture. For example, they sometimes accuse middle managers in front of their subordinates, leaving no face for these middle managers. This is unacceptable in our culture. On the other hand, they think we like to go around in circles, which to them is a waste of time." (Chinese Partner from venture A)

Professional values are formed based on past professional training, education and experiences, providing fundamental assumptions of how things are (Sirmon \& Lane, 2004; Hofstede, 1991; Karahanna et al., 2005). Professional values are often interrelated with national values, thus differ across national borders. Therefore professional values have considerable differences for partners from diverse cultures.

When comparing professional culture compatibility between ventures A, B (East-West joint ventures) and C (East-East joint venture), the findings suggest that venture $\mathrm{C}$ had the least trouble with professional culture compatibility. A foreign production manager from venture $\mathrm{C}$ stated: 
"There are minor differences for perceptions and work related attitudes between us. I mean, we can speak the same language and we have the same ancestors. Our logics are similar, and it's just things like perceptions over standards, values, and habits, etc., that are slightly different."

In venture $\mathrm{C}$, the issue of professional culture differences between partners still led to problems in areas like sharing of knowledge and transferring skills. However, in comparison to ventures $\mathrm{A}$ and $\mathrm{B}$, it requires a much shorter transitional period for establishing understandings between partners and their employees due to advantages in language and culture similarities.

“I don't see professional culture differences as a major obstacle in our venture.

There are really minor differences between us.” (Foreign partner from venture C)

The findings also suggest that social interactions between partners and their employees can assist with minimizing cultural differences:

"Employee interactions outside of work are very effective in our firm. These interactions helped us with communications both within and outside of work." (Foreign production manager in venture C) 
He continued:

"I guess this is also some form of establishing guanxi. You know, in China everything is guanxi and this works because they listen to you more and trust you more."

In contrast, the amount of social interactions between employees in the Sino-Western joint ventures was substantially lower. All participants in joint ventures A and B suggested that this was mainly caused by language barriers.

"There is very little we can share, and it's difficult to share... like local jokes, philosophies, etc.” (Foreign employee from venture B)

\begin{abstract}
"We do our business over dinner tables, and they do their business over conference tables. Such differences in habits may appear as no big deal, but such small things actually pull back our communication either in business or in private.” (Chinese partner from venture B)
\end{abstract}

Language barriers are not the only reason for an ineffective social interaction between employees in China-Western joint ventures. The Chinese partner from venture A pointed out that:

"Some Western people don't like to discuss work after work hours, and we don't mind that. When we try to socialize with them after working hours, we tend to discuss work related issues because that's all we can discuss really, and that sometimes makes them frustrated. For us (the 
management of the joint venture), it's slightly better because we would have translators beside us all the time. But our employees don't have translators."

This research found that greater professional and national culture compatibility between partners and partner employees exists for Eastern-Eastern joint ventures than Eastern-Western joint ventures. As can be seen from the case in venture C, language and cultural similarities provided a 'bridge' of shared understandings between partners and between their employees, whereas for ventures $\mathrm{A}$ and $\mathrm{B}$, there are no shortcuts and thus a bridge must be built from the beginning of the venture to establish this basis of shared understandings.

Following findings from Phase 1, this research also found evidence suggesting that the degree of employees' industry recognition alters the effectiveness in the sharing of knowledge and skills.

A few Chinese employees in venture B had previous experiences in working for other Sino-Foreign joint ventures in manufacturing chemicals or related products. In comparison to other non foreign experienced local workers, these employees are able to more effectively adapt to the new environment due to similar experiences in the past. One of these Chinese employees stated that: 
"The work here is quite similar to the last job I did. I was responsible to assist with quality control in my previous work, and I found that the techniques, methods, and technology for quality control here in many ways are similar to other China-Western joint ventures. So it took me shorter time to learn."

The Chinese partner in venture B suggested that:

"Our local employees with pre-existing foreign enterprise experiences have more understanding of Western business practices and values, which therefore contributes to a more effective transferring of knowledge between our partner and these employees. On the other hand, transferring and sharing of knowledge between our partner and local employees with no foreign experiences are much more difficult."

Also, the foreign partner from venture $\mathrm{C}$ said:

"When we train the Chinese workers and operations personnel, often it's easier to train the non-experienced as opposed to the experienced or professionals."

Overall, the findings broadly support Sirmon \& Lane's (2004) proposition that professional cultures are nation specific, and national cultural values significantly influence individual professional culture. The findings suggested that employees from similar national cultural backgrounds have greater professional culture compatibility than employees from diverse national cultural backgrounds. 


\subsection{The influence of partner employees' professional culture compatibility on the} relationship between related complementary resources and value creating

$$
\text { activity }
$$

Sirmon \& Lane's (2004) proposition argued that partner employees' professional culture negatively moderates the relationship between related complementary resources and the value creating activity. The findings from this research provided some detailed data supporting such a relationship.

The findings suggest that employees' professional culture differences negatively influence the sharing and combining of partners' related complementary resources, and as a result, it negatively influences the smooth running of the primary value creating activities. The foreign partner from venture A specifically pointed out that:

"Differences in our professional understandings caused some issues in the sharing of skills in our management team, consequently causing negative influences on our production."

However, the degree of this negative influence appears to depend on the type of primary value creating activity. For one case in particular, venture $\mathrm{B}$, the partners suggested that their primary value creating activity is not only production, but also marketing. The data collected from this case show a direct comparison of the effect of professional culture differences on the two primary value creating activities. 
All participants in venture B felt that transferring of knowledge and skills required less time in joint production than in joint marketing. The Chinese partner from venture B said:

"Cultural differences between employees are more problematic in our joint marketing operations than in production... I believe this is because marketing requires much more interaction and communication between employees than production."

"I believe my work is simpler when compared to the marketing group... the reason is probably because I deal with machines and they deal with people." (Foreign employee from Venture B)

"I think communication was not so good between us. This caused many difficulties in quotations, dealings with clients, promises we make, and service standards, etc. At one stage, bosses were quite concerned with the image and reputation of this company." (Chinese employee from venture B)

The foreign partner from venture A expressed similar opinions:

"I do not consider our professional cultural differences as a direct influence on our production (value creating activity). Like I said before, it's more indirect... because manufacturing jobs are not that complicated, there is no need for an extensive, ongoing interaction between people to manufacture our products." 
The findings suggested that professional culture differences between partners and partner employees can have negative influences on the smooth running of the venture's primary value creating activity. However, this negative influence changes according to the type of value creating activity. It appears to have a stronger negative influence on activities that require extensive interactions between employees in contrast to activities requiring fewer human interactions. Venture B specifically provided a good example for the comparison of professional culture influences on different types of primary value creating activities.

In general, the findings from this research support Sirmon \& Lane's (2004) proposition that employees' professional culture differences negatively moderate the relationship between related complementary resources and the effectiveness of joint ventures' value creating activity. The data from this research took Sirmon \& Lane's propositions slightly further by suggesting that employees' professional culture differences may have a stronger negative influence on value creating activities requiring significant ongoing exchange of knowledge and skills between employees, rather than those activities requiring lesser interactions. 


\subsection{Joint venture performance}

Following Yan \& Gray (1994), Table 4 provides a number of measurements for performance as well as considerable differences in strategic objectives between partners. Chinese partners generally focus on technology upgrades, foreign expertise, and foreign investments, while foreign partners seek low cost production, penetrating the local market, and earning a profit in China.

The diverse but complementary objectives noted above suggest that significant bias would occur if performance was measured from only one partner's perspective. Therefore, in this research, joint venture performance was assessed as the extent to which both partners are satisfied and had achieved their strategic objectives in starting the joint venture. Long term objectives were measured on the extent to which satisfactory progress had been made.

As a further check, I asked the partners what are their thoughts on my measurements for joint venture performance. Partners had no issues with this measurement technique. In particular, the Chinese partner from venture B said:

"It is important to ask the question: whether we are happy with what we are doing. I believe it is even more important than profitability." 
"I agree with how you measure performance. The only suitable method to measure performance is whether or not parent firms are happy with the joint venture ... not everything can be measured by profitability and market share." (Foreign partner from Venture A)

Table 4 summarizes information about performance assessments for the three joint venture cases.

Table 4: Joint Venture Performance Summary

\begin{tabular}{|c|c|c|c|}
\hline & \multicolumn{3}{|c|}{ Degree of Satisfaction } \\
\hline Strategic Objective & Joint Venture $A$ & Joint Venture B & Joint Venture $C$ \\
\hline \multicolumn{4}{|l|}{ Foreign Partner } \\
\hline Profit & High & High & High \\
\hline $\begin{array}{l}\text { Business } \\
\text { growth/Expansion }\end{array}$ & High & High & High \\
\hline Market share & & High & High \\
\hline Low cost & Medium & High & Very high \\
\hline Learning & & High & \\
\hline $\begin{array}{l}\text { Large scale } \\
\text { manufacturing }\end{array}$ & Low & & \\
\hline Overall Satisfaction & High & High & Very High \\
\hline \multicolumn{4}{|l|}{ Chinese Partner } \\
\hline New Technology & High & Medium & High \\
\hline $\begin{array}{l}\text { Business } \\
\text { growth/Expansion }\end{array}$ & Medium & Medium & High \\
\hline Export & High & Low & Medium \\
\hline Foreign Investment & & Medium & High \\
\hline Profit & High & Medium & High \\
\hline Technical Knowledge & Medium & Medium & High \\
\hline Foreign expertise & Medium & Medium & High \\
\hline $\mathrm{R} \& \mathrm{D}$ & & Low & \\
\hline Overall Satisfaction & Medium to high & Medium to Low & High \\
\hline
\end{tabular}


While Sirmon \& Lane (2004) argued that "the effectiveness with which the alliance achieves its primary value creating activities is a precursor of alliance performance, but that such primary value creating activities are specific to the purposes of specific international alliances" (p. 308), the evidence here suggests that this relationship is not as straightforward as they proposed. Smooth running of a joint venture's primary value creating activity does not always lead to positive performance for all partners. Below, I discuss each case individually.

\subsubsection{Venture A}

Firm A is the most recent joint venture of the three cases. Because this joint venture is relatively new, most of the partners' strategic objectives have not yet been fully achieved. For example, both large scale manufacturing and expected profit levels have not been reached. Therefore, these strategic objectives were measured on the extent to which the partners are satisfied with the progress made to date.

Regarding performance, the foreign partner is very satisfied with its primary strategic objectives. Venture A started to generate profit in their second year of operation. Their growth rate is steady and it is receiving very good customer feedback in recent times. As a result, the foreign partner in venture A is satisfied with the progress towards achieving their primary strategic objectives of profit and business growth. However, as discussed above, due to newness of venture A, final outcomes for 
strategic objectives such as profit and large scale production can only be measured by a partner's satisfaction over the progress of these objectives. This means that changes may occur in the future over the actual outcomes for their objectives. The foreign partner noted:

"We are happy with where we are. This joint venture is very young...there may be unpredictable issues in the future that can potentially challenge our strategic objectives. But as of this moment, we are happy with what's happening."

He continued:

“We haven't yet reached our ultimate strategic objectives, but we will get there in the future, I hope. We are heading towards healthy directions."

The Chinese partner is also satisfied with their primary strategic objectives. The Chinese partner is satisfied with the profit generated from the joint venture, and technology upgrades and transfer from their foreign partner, although the foreign partner still holds the key technology. The Chinese partner is also highly satisfied with exports. Almost $20 \%$ of profit comes from export, and that's something they did not have before the formation of this joint venture.

"We are satisfied with the additional benefits gained from this joint venture. If we didn't form this joint venture, we will not easily gain access to the international market. As you know, the image of Chinese companies, particularly manufacturing companies, is not very good. Foreign markets often consider 
Chinese companies as cheap and low quality. With the help of our foreign partner, we have upgraded our image globally. Their knowledge in the international market is strong, and we rely on them to open these markets." (Chinese partner from Venture A)

The Chinese partner is modestly satisfied with the business growth rate in comparison to what they already had prior to the joint venture formation. They noted that the rate of business growth was not as fast as they had expected. The Chinese partner continued:

"We have expectations and made plans before the formation of this joint venture.

Of course, many things in life don't go exactly according to plan, but we are fortunate to be on track for the large development directions."

The overall satisfaction for both partners in venture A was high. Despite performance satisfaction, the findings suggested that the running of venture A's primary value creating activity is not very effective. The participants in venture A said that they are still in a transitional period to establish a good basis of shared understanding between partners. The partners suggested that problems still exist particularly with communication between the partners, and this hinders the effectiveness in sharing of resources. 
"We still have problems. It's getting better but there is still huge room for improvements, including production efficiency, reducing cost, production timing etc." (Chinese partner from Venture A)

However the Chinese partner also indicated that:

"I can see that we are making good progress with communication. The visible progress between us and our foreign friends provided me with hope, and contributes greatly to my overall satisfaction with the joint venture."

The findings suggested a positive correlation between primary value creating activity and joint venture performance in the case of venture A, although the running of production in venture A is not yet very efficient. However, a trend of making progress in the effectiveness of sharing resources and running the primary value creating activity is seen to provide positive outcomes in partners' satisfaction levels on the overall joint venture performance.

\subsubsection{Venture B}

Venture B is a much larger scale joint venture when compared to venture A. It is a joint venture between two large and profitable organizations. Products/markets associated with venture B are 50\% local and 50\% export. Therefore, the primary value creating activity in venture B is not only production, but also joint marketing for 
both domestic and international markets. Satisfaction levels with performance in venture B differed between partners.

The foreign partner has achieved high satisfaction regarding its three most important strategic objectives: profit, business expansion, and learning. Especially with operating for many years in China, the foreign partner has gained significant knowledge about the local business environment. The foreign partner from venture B said:

"We have always wanted to enter the China market. We have excellent products, and the China market is a major step for our future. All of our stakeholders back home are very happy with how we positioned ourselves in this unique but exciting place ... we have achieved our strategic objectives for now."

He continued:

"We made good money these years. We have learned so much about this culture. It was hard at the beginning, but now is good ... cultural understanding is the key to successful co-operations in China. We are satisfied with this joint venture."

In contrast, the Chinese partner achieved very little regarding its main objectives, having only reached medium satisfaction over two of its three primary strategic objectives: technology upgrades and foreign investment. The other major objective for the Chinese partner was to export jointly produced products to foreign markets. In 
venture B, very little profit has been realized from their exports. Therefore, this objective has received a low satisfaction level from the Chinese partner. Other objectives such as profit, business growth, and R\&D support, had all received medium to low satisfaction rating from the Chinese partner. The Chinese partner commented:

"The joint venture is still profitable, it's just that we have much higher expectations, and we are not overly enjoying the venture's performance. Things like technology upgrades and profit are slightly better than what we had before the formation of this joint venture, but it is very far away from our original expectations. Overall, we are not very satisfied ... but because we have invested so much into this joint venture, it is also not realistic to pull out at this stage. To solve the problem, we will have to either change our satisfaction standards or make the joint venture better to meet our original objectives."

The Chinese partner was reluctant to discuss further possible causes of these unsatisfactory results. However, from discussions with employees from venture B, this research found that one reason that might have caused the controversial satisfaction levels for the partners may be the change in the power relations between partners. The foreign partner may have gained more bargaining power through learning, causing uneven results in performance satisfaction between employees. This would support a number of authors proposing a positive relationship between 
bargaining power and performance (Fisher and Ury, 1981; Blodgett, 1991; Yan \& Gray, 1994).

With regard to the primary value creating activities, both partners considered joint production and marketing to be effective in venture B at the time of the interviews. During the first few years, venture B had significant difficulties developing an effective base for shared understanding and resources between partners and their employees. As discussed earlier, the partners had required a long transition period that was costly and time consuming. However, both partners suggested that after the initial years, joint production and marketing became quite efficient. According to the partners, venture B's primary value creating activities were running smoothly at the time of this research. This, however, somewhat contradicts Sirmon \& Lane's (2004) proposition for the relationship between primary value creating activity and alliance performance. Further examination suggested a couple of reasons for this contradictory result. First, as discussed above, partner satisfaction over venture performance may differ from the venture's actual performance. In the case of venture B, the joint venture itself is successful in many respects. Overall, the joint venture is profitable, and growing at a steady pace. This, though, was not considered as successful by the Chinese partner because it did not reach their original expectations. Secondly, the venture receives very little profit from exports. According to one Chinese employee, this may have been due to: 
"strategies used by their foreign counterpart to promote more sales for other products not belonging to this joint venture. For example, the products exported from this joint venture were often used as give-away promotions for the purchase of other products belonging to the parent firm of the foreign partner."

The lack of progress on this performance dimension (accessing foreign markets) likely influenced the Chinese partner's satisfaction level, even though the venture's primary value creating activities were performing effectively. In this case, it appears more to do with the relationship between partners' management control and power (which represents a different research topic from this study).

Overall, in ventures A and B, the direct relationship between the effectiveness in the joint venture's primary value creating activity and venture performance does not appear to be as straightforward as predicted by Sirmon \& Lane (2004).

\subsubsection{Venture C}

Venture $\mathrm{C}$ displayed a more straightforward relationship between the primary value creating activity and the venture performance. Both partners in firm $\mathrm{C}$ established effective sharing of knowledge and skills in a short period of time, creating effectiveness in the running of the primary value creating activity. With respect to performance, venture $\mathrm{C}$ has been profitable since the very early stages. Sales and 
market share grew rapidly during the first few years, generating good profit for reinvestment. Over the years, both partners have reached their primary strategic objectives, and are very satisfied with the overall performance of the venture.

"We feel lucky to be in China developing our future. We have good profit, good market share, and good people to work with ... Culture differences had not influenced our co-operation. We are, however, fortunate to find a good partner in China. I know other Taiwanese firms that have failed in joint ventures with Chinese firms because of disloyalty, or because of misinterpretation of the communist government policies. Despite what the cause may have been, I haven't come across any Sino-Taiwan joint venture in China that failed due to cultural differences. There is really no significant cultural difference between us." (Foreign partner from Venture C)

"The performance in this joint venture is very good. We are ahead of many of our competitors, and our partners are very hard workers that motivated us to work even harder. I believe we have achieved our ultimate strategic objectives, now we are more focused on how we can stay ahead of the market." (Chinese partner from Venture C)

Venture $\mathrm{C}$ provided good evidence suggesting a positive relationship between a joint venture's primary value creating activity and performance. 
Overall, the results from all three cases tend to support Sirmon \& Lane's (2004) propositions. These three cases have provided some comparative examples of international joint ventures in China. The results suggest that partners from similar national culture backgrounds are less likely to face considerable differences in language and professional cultures, and, as a result, this positively influences the effectiveness in sharing of partners' complementary resources and the smooth running of the venture's primary value creating activity. The smooth running of the primary value creating activity then promotes higher satisfaction levels for both partners as to the performance of the joint venture.

On the other hand, partners from more diverse cultures appear to face greater differences in language, communication and professional understandings. Such differences tend to affect the time it takes to establish effectiveness in combining complementary resources and the smooth running of the primary value creating activity. Consequently in these joint ventures, the relationship between the effectiveness in the ventures' primary value creating activity and partners' satisfaction level on the venture's performance is not as straightforward. 


\section{Analysis, Discussion and Conclusion}

This chapter analyzes findings from both Phase 1 and 2 of this research. This chapter will conclude with limitations and future directions for this research.

\subsection{Phase 1}

Phase 1 of this research has contributed a variety of interesting findings. This has provided valuable initial knowledge in studying the influence of professional culture compatibility in China-Western joint ventures.

The findings from Phase 1 suggest that the understanding of professional culture in China must consider other areas beyond national culture. Professional cultures in China may be influenced by a variety of factors. For example, factors such as 'the nation's economic development' and 'the degree of interactions with foreign countries' should also be considered carefully in order to properly identify specific professional cultures. Therefore, this study expands Sirmon \& Lane's (2004) original model of 'cultural differences and international alliance performance'.

Based on practitioners' experiences in Phase 1, the findings have highlighted seven major contributing cultural characteristics of the complex Chinese national culture in 
the contemporary business environment (Table 2). Thus, the findings generated a framework of influential Chinese cultural factors on the contemporary business environment' that could then be used in Phase 2. The framework suggests that both Confucian and Daoist principles shaped the contemporary Chinese mind and its business environment. Previous studies suggested that Confucianism is the primary philosophy underlying the Chinese system (e.g. Street and Matelski, 2003, Chang \& Holt, 1991, Luo, 1997). However, the findings from this research illustrate similar, yet somewhat contradictory, results with Daoism exhibiting more influence than Confucianism in the modern Chinese mind. Out of the seven cultural factors in the proposed framework, four originated from Daoism. The findings suggest that Confucian principles still reflect on the surface of Chinese people, influencing people's actions towards how to conduct or expand businesses in China. Daoism, on the other hand, is more subtle and often hides below the surface, but it has significant influence on people's reactions towards business, especially towards business issues or problems. This may be indicative of the dynamic nature of cultures over extended periods of time and could be either a permanent or temporary shift. Thus, for modern managers, the influence of Chinese national culture characteristics on managerial behaviors may alter again, due to the pattern of interactions with the West and/or East. Many modern managers in recent times have been educated overseas (China Overseas Exchange Association Newsletter, 2005) and therefore extensive interaction beyond China's national boundary may change their values and practices in managerial behaviors in comparison with managers with less international experience. 
This was also supported by findings from Phase 2, where employees with past experience in foreign enterprises seemed to adjust to new Sino-Foreign joint venture environments more effectively compared to other local employees without foreign experience.

It is interesting to note that I have personally experienced the necessity of guanxi in China. My lack of guanxi created many obstacles when trying to find suitable participants for my research. Such experience itself provides further evidence supporting the importance of some of the Chinese cultural characteristics identified in Phase 1 of this research.

For the construct of professional culture in China, the findings suggest that the relationship between national culture and professional culture may be more complicated than previously proposed by Sirmon \& Lane (2004). This is illustrated in Model 2. 


\section{Model 2}

Factors influencing professional cultures in China

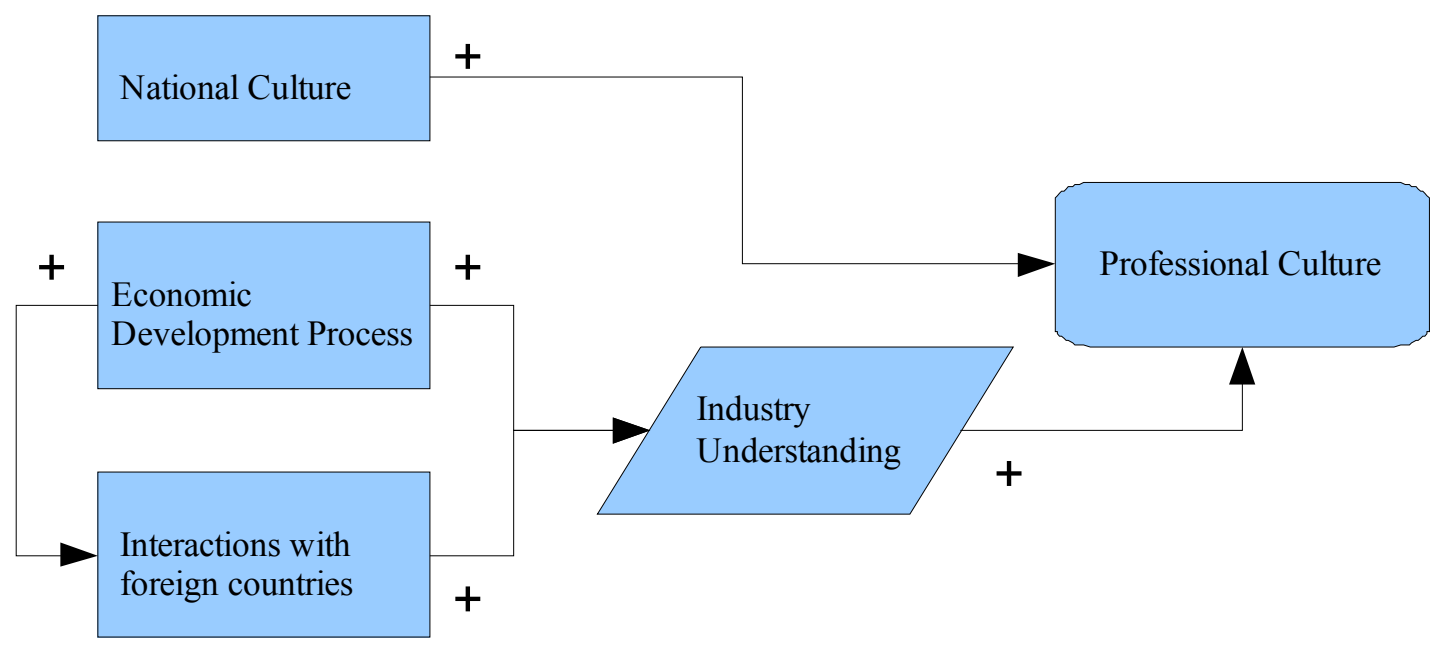

The findings from Phase 1 provided new factors along with national culture that appear to exhibit influential relationships on professional cultures in China (Model 2). The findings suggest that the process of economic development and interaction with foreign countries positively contribute to constant changes in numerous industrial statuses. Industrial prominence seems to then shape professional recognition within that industry, thus ultimately influencing the developments and changes in individual professional understandings, values, views, and attitudes.

As discussed in Chapter 2, Sirmon \& Lane's (2004) model indicated no direct influential relationship between organizational and professional culture. This contradicts from studies (e.g. Hofstede, 1984, 1991; Karahanna, 2005) which suggest that organizational and professional understandings are related to each other. In this 
study, the findings from Phase 1 suggest that the relationship between these two culture dimensions is moderated by the influence of industry understanding, where some values belonging specifically to an industry have the potential to influence both organizational and professional values within that industry. In cases where there are strong bonds between industry and organizations, it may be confusing at times to identify the differences in cultural influence, causing contradictory results amongst studies that include only one of these variables or fail to distinguish them fully.

The results here illustrate consistency with past studies regarding the influence of economic development on businesses, especially in developing economies (e.g. Lee \& Beamish, 1995; Li et al., 2001; Child \& Tsui, 2001). In particular, Li et al. (2001) argued that differences between developed and developing economies negatively moderate partners' culture compatibility in Sino-Foreign international joint ventures. The findings did not, though, identify specific characteristics belonging to all professional cultures in China. Professional culture characteristics are likely to vary across different professions which necessitate their identification separately for each profession. 


\subsection{Phase 2}

Phase 2 focussed on the relationship between partners' professional culture compatibility and the joint venture performance by analyzing three cases of Sino-Foreign joint ventures. Overall, these findings support Sirmon \& Lane's (2004) arguments closely on the influence/importance of partners' professional compatibility in international alliances.

This research also supports that national culture differences between partners negatively influence the effective sharing of partner resources (e.g. Pothukuchi et al., 2002; Sirmon \& Lane, 2004; Li et al., 2001; Parkhe, 1991). Findings suggest that partners from similar national culture backgrounds require less time for a transitional period to establish a basis of shared understanding and knowledge. Much more time is required for this transitional period by partners from diverse national cultural backgrounds.

Also, following findings from Phase 1, Phase 2 found traces of different culture characteristics between collective and individualistic cultures, for example the avoidance of direct confrontation vs. direct confrontation. Consistent with Chen et al. (1998) and Morris et al. (1998), this research found that national culture differences between collective and individualistic cultures could result in diverse work and 
professional habits between partners and their employees, and consequently, negatively influence their effectiveness in sharing.

Based on the findings, this research would argue for an updated integrated model of partners' professional culture compatibility and its effects on international joint venture performance (Model 3). Model 3 combines the original model proposed by Sirmon \& Lane (2004) and the findings from Phase 1 and 2, including the construct of professional culture and the relationships between all factors and joint venture performance.

\section{Model 3}

Integrated model of professional culture compatibility and international joint venture performance

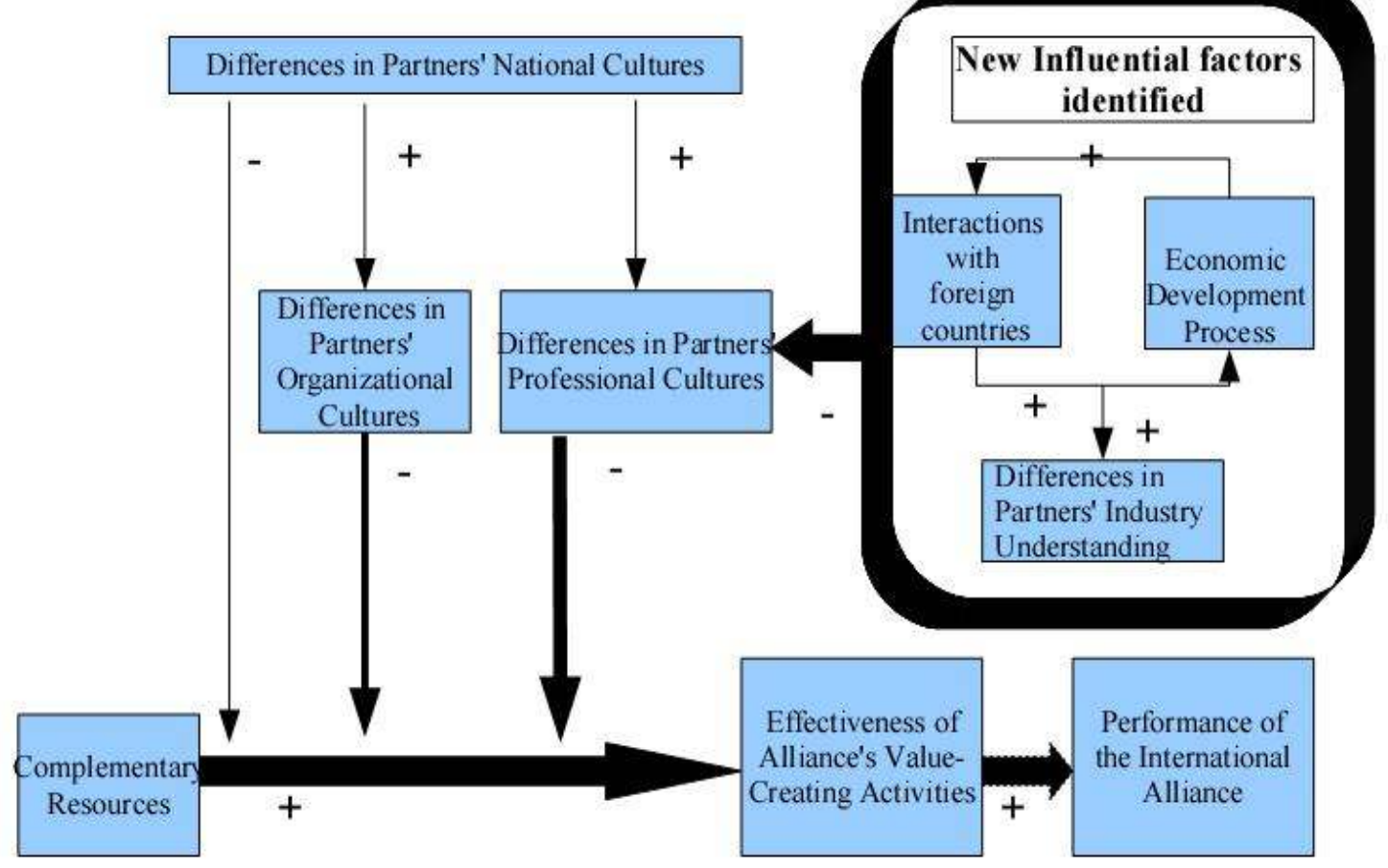


This research illustrated that joint ventures from similar cultural backgrounds enjoy better compatibility of partners' professional cultures as opposed to joint ventures from diverse cultural backgrounds. Results suggest that Sino-Eastern joint venture in China showed better sharing of resources and communication between partners and employees compared to Sino-Western joint ventures. In particular, this research found no significant difference in work habits or obstacles in employee interactions in the Sino-Eastern joint venture, although the small sample must be remembered. In contrast, Sino-Western joint ventures showed difficulties in working and communicating (not only with language barriers, but also professional habits, work values, etc.) with their Chinese counterpart.

Drawing on the findings from Phase 2, this research suggests that partner employees' differences in professional culture can hinder effective communication and transactions of knowledge within the joint venture, and differences in partner employees' professional culture and past industry experiences appear to have considerable negative impact on the relationship between resource complementarity and the primary value creating activity. However, the degree of this negative influence will likely depend on the type of primary value creating activity. The findings suggest that partners' professional culture compatibility has more influence on the venture's primary value creating activity when these involve significant human interactions. Professional culture compatibility primarily concerns the sharing of professional knowledge and skills, which will require employee interaction. Therefore, 
professional culture compatibility would have more influence when the primary value creating activity involves significant human interactions (e.g. joint marketing, sales, R\&D), than those joint activities with fewer interactions among partner employees (e.g. dealing primarily with machines and equipment).

For the relationship between the partner resources, the venture's primary value creating activity, and venture performance, Sirmon \& Lane (2004) argued that:

“The complementarity of partners' resources positively affects alliance performance only when those resources are related to the primary value-creating activities of the international alliance" (p. 309)

Data from this research supports the above argument. However, differing to Sirmon \& Lane's argument, this research found that partners stress the importance of all resources, not limiting this to only the related partner resources.

Furthermore, augmenting the culture similarities in Sino-Eastern joint ventures, the findings suggest that language is an important barrier in sharing of knowledge between partners. Language advantages can significantly reduce time and effort to establish a basis of understanding between partners, thus promoting a better sharing of complementary resources. Many Sino-Eastern joint ventures enjoy such language advantages (e.g. Taiwan, Singapore, Malaysia), where Mandarin is extensively used by employees in the workplace. Language similarities between partners promote better employee interactions both within and outside work. The data suggested that 
employee interaction outside work increases the effectiveness in sharing of knowledge and skills, in particular when compared to Sino-Western joint ventures in China where little employee interaction exists outside of work, likely due to language barriers.

Based on the partners' satisfaction levels with joint venture performance, when compared to Sino-Western joint ventures, this research has illustrated a more straightforward relationship in Sino-Eastern joint ventures between the smooth running of the venture's primary value creating activity and the venture's performance. As proposed in the methodology section, a joint venture is only considered successful in performance when both partners showed satisfaction over performance and they have reached the original strategic objectives for the formation of the joint venture. The Sino-Eastern joint venture showed better compatibility between the partners' professional cultures and effective sharing of related resources. This, in turn, appears to provide a platform for the joint venture to exhibit a clear positive relationship between the effectiveness in running the joint venture's primary value creating activity and the venture's performance. When compared with partners from more similar cultures, Sino-Western joint ventures illustrated more difficulties in sharing of knowledge and skills between partners and, as a result, tended to show lesser and contradictory satisfaction levels between partners when analysing these joint venture performances. Therefore, referring to the second research question, this study has provided preliminary evidence that professional culture differences between 
joint venture partners and partner employees can negatively influence the overall performance of the joint venture.

\subsection{Limitations and future research}

The limitations to this research should also be recognized and this understanding can be employed by future studies to further investigate this study topic.

First, the number of cases was not as high as desired. Eisenhardt (1989) states that the number of cases or subunits appropriate for a well justified study is between four and ten. Due to difficulties in securing participation by both Chinese and foreign partners in the international joint ventures, this research was limited to only three joint venture cases that were willing to participate. This, however, constitutes six partners that provided their perspective on the key areas of study. It does, though, mean that applying a large number of choice and selection criteria for suitable participating cases was not an option for this research. Because of the limited data available for examination, this has largely limited the generalization of the findings and the research's ability to more fully assess reliability. Future research can utilize the findings from this research to examine further cases and data. The integrated model (Model 3) requires more examination on a much larger scale with samples of 
Sino-Foreign joint ventures (with both more similar and divergent professional cultures).

Second, the findings from this research were based only on Sino-Foreign joint ventures in China, and several factors related to the China environment could not be examined due to time and financial constraints. Phase 1 suggested that the degree of the nation's economic development and its interaction with foreign countries may constitute influential relationships shaping professional cultures. The influence of these factors may change over time or differ across nations. Therefore, the generalization of the preliminary findings from this research to other joint ventures in other countries should be made with caution.

Third, this study was not longitudinal. Additional research using longitudinal data is needed to clarify joint venture performance over time. Particularly, one of the cases under investigation was in a transition period from the time of its establishment, and there may be many unforeseen factors which could alter the performance of that joint venture and, thus, consequently augment the results of this research. Therefore, the findings would be more reliable if these joint venture cases could have been visited across a range of time, from nearer inception to several years after that or even termination. In addition, China has experienced significant economic development in the past couple of decades ( $\mathrm{Li}$ et al., 2001). Thus, it would be beneficial to examine 
culture influences in Sino-Foreign joint ventures on a longitudinal basis taking into consideration such changes in economic development.

Fourth, this research investigated the direct influence of culture differences on international joint venture performance, but it did not examine other influences such as partners' power relations and management control (e.g. Yan \& Gray, 1994; Fisher and Ury, 1981; Blodgett, 1991), primarily because this would have required even greater access into the organizations. Previous research suggests that these influences may also alter partners' satisfaction levels over performance. As a result, it is unknown at this stage whether an influential relationship exists between these factors and culture compatibility between partners. Therefore, future research would benefit by taking these additional factors into consideration and perhaps even investigate the relationship between these factors and culture differences between international joint venture partners, and their influences on joint venture performance.

Fifth, this research relied primarily on perceptions of participants to examine joint venture performance. Future studies may benefit more by gaining access to more objective performance measures such as profit or survival. Particularly, the findings from this research illustrate differences between perceived performance by partners and the actual performance of the joint venture (Case B). 
In addition, although this research found a positive connection between the smooth running of the venture's primary value creating activity and the joint venture performance, with the analyses based on only three cases, this conclusion should be made with caution. At the time of this research, most partners have suggested that their venture's primary value creating activity is running smoothly. Therefore, it is important for future research to have more in-depth comparisons for the relationship between the venture's performance with both effectiveness and ineffectiveness in running the venture's primary value creating activity. Without more points of contrast between successful and ineffective primary value-creating activities, it is too early to make definitive conclusions on this relationship.

Finally, this research was restricted to manufacturing joint ventures. Future research on Sino-Foreign joint ventures needs to investigate the applicability of the models proposed to a variety of other industries (e.g. services, IT, etc.).

Furthermore, industry understanding has been identified in this research as a potentially influential factor on the overall performance of the joint venture. Therefore, future studies can benefit from more examination of the partners' understandings of the industry when analyzing the influence of partner culture in international alliance performance. 
This research has identified a number of contributing factors towards individual professional cultures. Although the findings have illustrated an influential relationship between partners' professional culture compatibility and joint venture performance, professional cultures appear idiosyncratic and because of this, the findings from this research remain incomplete. The findings from Phase 1 suggest that it is difficult to measure professional culture in general because every profession constitutes a distinct set of values and practices within a national boundary. Therefore, future research may benefit from focusing the comparisons on a single profession (e.g. accountants, R\&D scientists, etc.) between partner employees across numerous international joint ventures.

In addition, this research did not simultaneously examine the influence of different cultural levels on international alliance performance. Therefore, this research did not fully examine Sirmon \& Lane's (2004) model. Sirmon \& Lane (2004) argued that professional culture differences have the strongest negative influence on alliance performance comparing to national and organizational culture differences. To fully examine their model, future research can utilize the findings from this research and take it further by simultaneously examining other culture levels such as national and organizational culture to compare and determine whether professional culture differences between partners represent the most negative influence on international alliance performance. 


\subsection{Managerial Implications}

International joint ventures offer competitive and strategic advantages for firms entering foreign markets (Hollensen, 2004). In China, joint ventures are the most common form for foreign investments (Yan \& Gray, 1994), and thus the understanding of international joint ventures in China represents great importance for foreign firms seeking to enter the Chinese market. This study therefore offers some implications for managers.

Joint venture performance has always been a major concern for both academics and managers (Pothukuchi et al., 2002). Based on the findings, this research echoes the importance of professional culture compatibility on joint venture performance. According to Sirmon \& Lane (2004) and Karahanna et al. (2005), professional culture compatibility between partners is more problematic than organizational culture. Organizational culture consists primarily of organizational practices, and professional culture involves a balance of professional practices and values. While practices can change over time, professional norms and values are more difficult to change (Karahanna et al., 2005) providing a strong driver of decisions and actions. Thus, procedures for developing a base of shared understandings are very important in Sino-Foreign joint ventures. A transitional period may be required to establish this understanding between partners and their employees. As such periods represent high 
cost and low outcome for joint ventures, managers need to focus on reducing the time to more effectively combine partner resources and understandings.

This research also provides in-depth understanding of key Chinese culture characteristics that shape the contemporary Chinese business environment. Past studies that suggested Confucianism is the major school of thought shaping the Chinese business mind (Luo, 1997; Street \& Matelski, 2003; Redding \& Wong, 1986). This study, however, found that Daoism has the same or even stronger importance in shaping Chinese business thinking. This suggests that foreign managers may need to also focus on the teachings of Daoism if one wishes to understand and interact with the Chinese business environment and thinking.

One method to overcome cultural distance issues is to employ dedicated managers who have good understandings of both cultures. Consistent with Li et al.'s (2001) recommendation, these managers may improve communication between partners and help to reduce the time for an effective sharing of resources between partners. Particularly for professional culture compatibility, it appears important for both partners to employ professionals with strong international experience. For example, the findings suggested that Chinese managers/employees with past experience in foreign firms can adapt more effectively to a new Sino-Foreign joint venture environment as opposed to managers/employees with only local experiences. This suggests that by employing these professionals, the joint venture can reduce the time 
and cost taken to establish higher effectiveness in combining partner knowledge resources. Furthermore, this research suggests managers should keep in mind that professional culture compatibility between partners and partner employees is likely to have greater influences on joint activities involving more human interactions. Thus, if one wishes to establish joint venture activities that require significant communication and sharing between partners and their employees (e.g. R\&D, sales), the understanding of partners' professional culture then becomes extremely important.

Furthermore, language has been identified as another important barrier for partners from diverse cultures. To overcome this issue, partners can employ managers with bilingual abilities (e.g. fluent in both English and Mandarin), which can help with communication between partners and partner employees both within and outside the work environment. The findings from this research suggested that employee interactions outside work can positively influence the effectiveness in sharing of knowledge and skills; this again can reduce time and cost for a transitional period to establish a shared basis of understandings between partners.

Apart from partner's culture compatibility, this research highlights that partners can benefit from having clear strategic objectives when forming the joint venture. The findings suggest that even with the presence of good culture compatibility and effective sharing in resources, this may not always provide satisfaction for both partners. Culture compatibility may not be the only area of importance for partners to 
be satisfied with the joint venture. Therefore other areas must also be looked at from both practical and theoretical perspectives, such as changes in bargaining power and management control and trust (Yan \& Gray, 1994). Culture compatibility and good communication may assist with minimizing issues such as partnership trust (Pothukuchi et al., 2002). However, to fully comprehend the factors contributing to a successful joint venture, both practitioners and theorists must integrate and examine all related areas.

\subsection{Theoretical implications}

In terms of theory, this research has contributed to existing culture studies in international alliances. The concept of professional culture compatibility between partners is a new study area with little past empirical data collection (Sirmon \& Lane, 2004). Following Sirmon \& Lane (2004), this research examined the influence of partners' professional culture compatibility on international joint venture performance. The results here support Sirmon \& Lane's (2004) propositions and are consistent in confirming the importance and influence of partners' professional culture compatibility on international joint ventures.

This research extends Sirmon \& Lane's (2004) original model in suggesting new contributing factors and relationships to professional culture and performance in 
international joint ventures. The integrated model developed by this research also supports a number of other studies. For example, the findings from this research also point to the importance of economic development in shaping culture, which supports studies such as Li et al. (2001) and Tsui et al. (2006) where these studies also argue that the understanding of economic development, particularly in developing economies such as China, is critically important for foreign companies hoping to establish successful joint ventures with local firms.

The integrated model developed from this research offers a good foundation for future studies to further examine the concept of partners' professional culture compatibility in international joint ventures. It is interesting that the findings from this research suggest that good performance and effective running of the primary value creating activity in joint ventures may not always provide satisfaction for both partners. Therefore, it is important for future research to consider the importance of other factors such as power, control and trust issues when analyzing partner satisfaction. In addition, future research in measuring performance may benefit from also analyzing more objective measures such as survival and financial outcomes (where possible) to incorporate a broader based perspective from both partners. 


\subsection{Closing Statement}

International joint ventures are the most common form of international alliances. Such forms have received interest from a variety of academic disciplines (Yan \& Gray, 1994). This research focused on cultural issues in international joint ventures in China with a particular focus on professional culture. China has experimented with alternative models to generate rapid economic growth, and it is now one of the most popular foreign investment destinations, and seems destined to become one of the greatest markets in the world (Huang, 2004).

This research investigated the influence of partners' professional culture compatibility on international joint venture performance by analysing three case studies (six firms) of Sino-Foreign joint ventures in China. Sirmon \& Lane's (2004) model of culture differences and international alliance performance is the fundamental thinking behind this research. Because Sirmon \& Lane's (2004) propositions have not received any form of empirical examination, this study has provided a step towards addressing this research gap and elaborating their model. The purpose of this research was to examine the new concept, proposed by Sirmon \& Lane (2004), of professional culture compatibility between partners and its influence on international alliance performance utilizing data collected from three Sino-Foreign joint ventures cases in China. 
The findings from this research provided an integrated model of partner professional culture compatibility and international joint venture performance (Model 3). This integrated model has extended Sirmon \& Lane's (2004) model, and provided further support for Sirmon \& Lane's argument on the influence and importance of partners' professional culture compatibility on international alliance performance.

This research has hopefully provided a useful step forward in how to measure professional cultures and compatibility, their effects on performance, some factors affecting professional cultures within industries, and an updated understanding of contemporary Chinese cultural influences. I hope that this will form a useful platform for future research. 


\section{References}

Abdahlla, D. A. (2002). The decision making process among Chinese (The People's Republic of China) management. A Dissertation for the degree of PH.D. in Organizational Philosophy, Alliant International University

Annual Report 2006. The State Administration of Foreign Experts Affairs, P. R. China: Beijing Head Office

Barkema, H., \& Freek, V. (1997). 'What differences in the cultural backgrounds of partners are detrimental for international joint ventures?', Journal of International Business Studies, 28 (4): 845-864

Beamish, P. W. (1993). 'The characteristics of joint ventures in the People's Republic of China', Journal of International Marketing, 1 (2): 29-48

Blodgett, L. L. (1991). 'Partner contributions as predictors of equity share in international joint ventures'. Journal of International Business Studies, 22 (1): $63-78$

Brown, L., Rugman, A., \& Verbeke, A. (1988). 'Japanese joint ventures with Western multinationals: Synthesizing the economic and cultural explanations of failure', Journal of Pacific Asian Management, 6: 225-242

Caloghirou, Y., Hondroyiannis, G., \& Vonortas, N.S. (2003). 'The performance of research partnerships', Management and Decision Economics 24: 85-99

Cavana, R.Y., Delahaye, B.L. \& Sekaran, U (2001). Applied Business Research: Qualitative and Quantitative Methods. Milton: Wiley \& Son 
Chan, W. T. (1967). 'The individual in Chinese religions'. In Morehead, C. A. (Ed). The Chinese mind, Honolulu, University of Hawaii Press

Chang, H. C., \& Holt, R. (1991). 'More than relationship: Chinese interaction and the principle of Kuan-Hsi’. Communication Quarterly, 39: 251-271

Chang, L. Y., \& Tam, T. (2004). 'The making of Chinese business culture: Cultural versus organizational imperatives'. In Gomes, E. T, and Tsiao, H-H. M. (Eds). Chinese Enterprise, Transnationalism, and Identity: 23-38. London: RoutledgeCurzon

Chen, C.C., Chen, X.P., Meindl, J.R. (1998). 'How can cooperation be fostered? The cultural effect of individualism-collectivism'. Academy of Management Reviews, 23 (2): $285-304$

Chen, M. (1995). Asian management systems: Chinese, Japanese, and Korean styles of business. New York: Routledge

Child, J. (1995). 'Management in China: Economy and system'. In D. J. Hickson (Ed.), (1997). Exploring Management across the World. London: Penguin Group

Child, J., \& Tse, D. K. (2001). 'China's transition and its implications for international business'. Journal of International Business Studies, 32 (1): 5-21

China Overseas Exchange Association Newsletter (2005). August Edition. Beijing

Cummings, B. (1984). The Two Koreas. New York: Foreign Policy Association

Das, T.K., \& Tend, B-S. (2000). 'A resource-based theory of strategic alliances'. Journal of Management, 26: 31-61. 
Das, T.K., \& Teng, B-S. (1998). 'Between trust and control: Developing confidence in partner cooperation in alliances'. Academy of Management Review, 23 (3): $491-512$

Derr, C. B., \& Laurent, A. (1989). The internal and external career: A theoretical and cross-cultural perspective. In Arthur, M., Lawrence, P. R. and Hall, D. T. (Eds). Handbook of Career Theory. Cambridge: Cambridge University Press

Eisenhardt, K. M. (1991). 'Better stories and better constructs: The case for rigor and comparative logic'. Academy of Management Review, 16 (3): 620-627

Eisenhardt, K. M. (1989). 'Building theories from case study research'. Academy of Management Review, 14 (4): 532-550

Erez, M., \& Earley, P.C. (1993). Culture self identity, and work. New York: Oxford University Press

Fisher, R., \& Ury, W. (1981). Getting to yes: Negotiating agreement without giving in. New York: Penguin Group

Geringer, J. M., \& Hebert, L. (1991). 'Measuring performance of international joint ventures'. Journal of International Business Studies, 22(2): 249-263

Giamartino, G. (1991). 'Will small business be the answer for developing economics?'. Journal of Small Business Management, 29 (1): 91-93

Gilbert, M. G. (1978). Great religions of the world. Washington, D. C: National Geographic Society 
Goodman, P., \& Pennings, J. (1980). 'Critical issues in assessing organizational effectiveness'. In Lawler, E., Nadler, D. and Cammann, C. (Eds.). Organizational Assessment: 185-215. New York: Wiley-Interscience

Hagedoorn, J. (1993). 'Understanding the rationale of strategic technology partnering: Inter-organizational modes of cooperation and sectorial differences', Strategic Management Journal, 14 (5): 371

Hamel, J., Dufour, S., \& Fortin, D. (1993). Case study methods. Newbury Park: Sage.

Henderson, D. F. (1975). Foreign enterprise in Japan. Chapel Hill: University of North Carolina Press

Hitt, M. A., Tyler, B. B., Hardee, C., \& Park, D. (1995). 'Understanding strategic intent in global market place'. Academy of Management Executive, 9 (2): 12-19

Ho, D. Y. F. (1994). 'Filial piety, authoritarian moralism, and cognitive conservatism in Chinese societies'. Genetics, Social, and General Psychology Monographs, 120: $347-365$

Hofstede, G. (1991). Cultures and organizations: Software of the mind. London: McGraw-Hill

Hofstede, G. (1984). Culture's consequences: International differences in work-related values. Newbury Park: Sage

Hollensen, S. (2004). Global marketing: A decision-oriented approach. Third Edition. Europe: Prentice Hall 
Huang, J., \& Cullen, J.B. (2001). 'Labour flexibility and related HRM practices: A study of large Taiwanese manufacturers'. Canadian Journal of Administrative Science, 18 (1): 33-53

Huang, L. (2004). Building the bridge between New Zealand and China: An exploratory study of business networks. A research project for the degree of MMS, Victoria University of Wellington

Hui, C. H., \& Tan, C. K. (1996). 'Employee motivation and attitudes in the Chinese workforce'. In Bond, M. H. (Ed.). Handbook of Chinese Psychology. Hong Kong: Oxford University Press

Inkpen, A. C., \& Beamish, P. W. (1997). 'Knowledge, bargaining power and international joint venture stability'. Academy of Management Review, 22: $177-202$

Johnson, J.L., Cullen, J.B., Sakano, T., \& Takenoushi, H. (1996). 'Setting the stage for trust and strategic integration in Japanese-US cooperative alliances'. Journal of International Business Studies, 27: 981-1004

Karahanna, E., Evaristo, J.R., Srite, M. (2005). Levels of culture and individual behavior: An integrative perspective. Journal of Global Information Management, $13(2): 1-20$

Kedia, B., Keller, R., \& Julian, S. (1992). 'Dimensions of national culture and the productivity of R\&D units'. Journal of High Technology Management Research, $3(1): 1-18$

Killing, J. P. (1983). Strategies for Joint Venture Success. New York: Praeger 
Lane, H.W., Beamish, P.W. (1990). 'Cross cultural cooperative behaviour in joint ventures in LDCs'. Management International Review, 30: 87-102

Laurent, A. (1983). 'The cultural diversity of Western conceptions of management'. International Studies of Management and Organization, 13 (2): 75-96

Lecraw, D. J. (1984). 'Bargaining power, ownership, and profitability of transnational corporations in developing countries'. Journal of International Business Studies, 15 (1): $27-43$

Lee, C., \& Beamish, P. W. (1995). 'The characteristics and performance of Korean joint ventures in LDCs'. Journal of International Business Studies, 26 (3): $637-654$

Li, J., Khatri, N., \& Lam, K. (1999). 'Changing strategic postures of overseas Chinese firms in Asian emerging markets'. Management Decision, 37: 445-456

Li, J., Lam, K., \& Qian, G. (2001). 'Does culture affect behavior and performance of firms? The case of joint ventures in China', Journal of International Business Studies, 32 (1): 115-131

Lin, X. (2004). 'Determinations of cultural adaptation in Chinese-U.S. joint ventures'. Cross Cultural Management, 11 (1): 35-47

Lincoln, Y., \& Guba, E. (1985). Naturalistic Enquiry. Beverly Hills: Sage

Luo, Y. (1995). 'Business strategy, market structure, and performance if international joint ventures: The case of joint ventures in China'. Management International Review, 35: 241-264 
Luo, Y. (1997). 'Partner selection and venturing success: The case of joint ventures with firms in the People's Republic of China'. Organizational Science, 8: 648-662

Luo, Y., Shenkar, O., \& Nyaw, M-K. (2001). 'A dual parent perspective on control and performance in international joint ventures: Lessons from a developing economy'. Journal of International Business Studies, 32 (1): 41-58

Luostarinen, R. (1980). Internationalization of the Firm: An empirical study of the internationalization of firms with small and open domestic markets with special emphasis on lateral rigidity as a behavioral characteristic in strategic decision-making. Helsinki: The Helsinki School of Economics

Mead, R. (1995). International Management: Cross-cultural Dimensions. Oxford: Blackwell

Mei. Y. P. (1986). 'The basis of social, ethical, and spiritual values in Chinese philosophy'. In Moore, C. A. (Ed.). The Chinese Mind: Essentials of Chinese Philosophy and Culture. Honolulu: University of Hawaii Press

Miles, M.B., \& Huberman, A.M. (1994). Qualitative Data Analysis. London: Sage

Morris, M. W., Williams, K. Y., Leung, K., Larrick, R., Mendoza, M. T., Bhatnagar, D., Li, J., Kondo, M., Luo, J. L., Hu, J. C. (1998). 'Conflict management style: Accounting for cross-national differences'. Journal of International Business Studies, 29 (4): 729-747

Nevis, E. C. (1983). 'Using an American perspective in understanding another culture: Towards a hierarchy of needs for the People's Republic of China'. Journal of Applied Behavioural Science, 19: 249-264 
O’Reilly, C., \& Chatman, J. (1996). 'Culture as social control: Corporations, cults, and commitment'. In Staw, B. and Cummings, L. (Eds). Research in Organizational Behaviour, 18: 157-200

Pan, Y. (1997). 'Environment risk and foreign equity ownership in joint ventures in China'. Journal of Asia-Pacific Business, 2 (2): 23-41

Pan, Y., \& Chi, P. S. (1999). 'Financial performance and survival of multinational corporations in China'. Strategic Management Journal, 20 (4): 359-374

Pan, Y., \& Tse, D. K. (1996). 'Cooperative strategies between foreign firms in an overseas country'. Journal of International Business Studies, 27 (5): 929-946

Park, S. H., \& Ungson, G. R. (1997). 'The effect of national culture, organizational complementarity, and economic motivation on joint venture dissolution'. Academy of Management Journal, 40 (2): 279-307

Parkhe, A. (1991). 'Interfirm diversity, organizational learning, and longevity in global strategic alliance'. Journal of International Business Studies, 22 (4): $579-601$

Pothukuchi, V., Damanpour, F., Choi, J., Chen, C. C., \& Park, S. H. (2002). 'National and organizational culture differences and international joint venture performance'. Journal of International Business Studies, 33: 243-265

Qu, R., \& Zhang, Z. (2005). 'Work group emotions in Chinese culture settings'. Singapore Management Review, 27 (1): 69-86

Rao, A., \& Schmidt, S. M. (1998). 'A behavioural perspective on negotiating international alliances'. Journal of International Business Studies, 29 (4): 665-694 
Redding, G. (1990). The spirit of Chinese capitalism. Berlin: Walter de Gruyter \& Co

Redding G., \& Wong, G. Y. Y. (1986). 'The Psychology of Chinese organizational behaviour'. In Bond, M. H. (Ed.). The Psychology of the Chinese People. New York: Oxford University Press

Scarborough, J. (1998). The origins of cultural difference and their impact on management. Westport: Quorum Books

Schaan, J. L. (1988). 'How to control a joint venture even as a minority partner'. Journal of General Management, 14 (1):4-16

Shenkar, O., \& Ronen, S. (1987). 'The cultural context of negotiations: The implications of Chinese interpersonal norms'. Journal of Applied behavioural Sciences, 23: 263-275

Singh, K. (2007). 'The limited relevance of culture to strategy'. Asia Pacific Journal of Management 24 (4): 421-428

Sirmon, D. G., \& Lane, P. J. (2004). 'A model of cultural differences and international alliance performance'. Journal of International Business Studies, 35 (4): $306-319$

Smith, H. (1994). The illustrated world's religions: A guide to our wisdom traditions. New York: Harper Collins

Sparrow, P., \& Wu, P. C. (1998). 'Does national culture really matter? Predicting HRM preferences of Taiwanese employees'. Employee Relations, 20 (1): 26-45 
Street, N. L., \& Matelski, M. J. (2003). American Businesses in China: Balancing Culture and Communication. North Carolina: McFarland

Tellis, W. (1997). 'Introduction to case study'. The Qualitative Report 3 (2): 1-13

Terpstra, V., \& David, K. (1991). The Cultural Environment of International Business. Third edition. Cincinnati: South-Western

Thompson, L. G. (1975). Chinese religion: An introduction. Second edition. Encino \& Belmont: Dickenson

Triandis, H.C. (1972). The analysis of subjective culture. New York: Wiley \& Son

Trice, H. M., \& Beyer, J. M (1993). The Culture of Work Organizations. Englewood Cliffs, NJ: Prentice Hall

Tsang, E. W. K. (1998). 'Can guanxi be a source of sustained competitive advantage for doing business in China?'. Academy of Management Executive 12 (2): 64-73

Tse, D. K., Pan, Y., \& Au, K. Y. (1997). 'How MNCs choose entry modes and form alliances: The China experience'. Journal of International Business Studies, 28 (4): $779-805$

Tsui, A. S., Wang, H., \& Xin, K. R. (2006). 'Organizational culture in China: An analysis of culture dimensions and culture types'. Management and Organization Review 2 (3): 345-376

Very, P., Lubatkin, M., \& Calori, R. (1996). 'A cross-national assessment of acculturative stress in recent European mergers'. International Studies of Management and Organization, 26 (1): 59-86 
Walff, J. A., \& Reed, R. (2000). 'Firm resources and joint ventures: What determines zero-sum versus positive-sum outcomes?'. Managerial and Decision Economics, 21 (7): $269-284$

Yan, A. (1998). 'Structural stability and reconfiguration of international joint ventures'. Journal of International Business Studies, 29 (4): 773-796

Yan, A., \& Gray, B. (1994). 'Barganing power, management control, and performance in United States-China joint ventures: A comparative case study'. Academy of Management Journal, 37 (6): 1478-1517

Yin, R. (1984). Case study research: Design and methods. Beverly Hills: Sage

Yin, R. (1994). Case study research: Design and methods. Second edition. Beverly Hills: Sage

Yum, J. O. (1991). 'The impact of Confucianism on interpersonal relationships and communication patterns in East Asia'. In Samora, L. A. and Porter, R. E. (Eds.). Intercultural Communication: A Reader. Sixth edition. Belmont: Wadsworth

Zhang, J., \& Bond, M. H. (1998). 'Personality and filial piety among college students in two Chinese societies'. Journal of Cross Cultural Psychology, 29 (3): 402-417 


\section{Appendix 1:}

\section{Victoria \\ UNIVERSITY OF WFILINGTON \\ Te Whare Wananga \\ o te Üpoko o te Ika a Maut

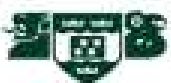

\section{Interview Outline}

\section{Joint venture characteristics}

Questions for both partners of the joint venture

- How many employees currently work in this joint venture?

- What is the employee ratio from both partners?

- When was this joint venture formed?

- What was the reason underlying the formation of this joint venture?

- What is your main manufacturing product?

\section{Partners' relationship}

- What is the ownership structure of this joint venture?

- Were there any changes in the ownership structure of this joint venture?

- (If changes occurred) What have caused these changes?

- Can you please describe each partner's role in this joint venture?

\section{Complimentary resources}

- Can you please describe different resources each partner brings into the joint venture?

Tangible resources?

Intangible resources?

- How important was these complimentary resources to the running and development of this joint venture?

Tangible resources?

Intangible resources?

- How effective was the sharing and combing of these resources?

$\checkmark$ Between the management team of the joint venture?

- Between workers/employees of the joint venture?

\section{Value creating activities}

- Is production the primary value creating activity of this joint venture? (Because this research is based on the manufacturing sector, therefore I assume that the primary value creating activity is production. However, I must confirm this with the participants).

- What are the roles of each partner's employee's involvement in the primary value creating activity? 
- How effective is the running of the primary value creating activity?

(If production is the primary value creating activity)

$\checkmark$ On time production?

$\checkmark$ Inventory turnover?

$\checkmark$ Production quality?

- Do you think an influential relationship exist between the effectiveness in sharing/combining of complimentary resources (both tangible and intangible) and the effectiveness in the running of the joint venture's primary value creating activity?

\section{Professional culture between partner employees}

- The joint venture partners and their employees are from different cultural backgrounds, and generally does this represent differences in how they work?

$\checkmark$ Work related attitude and values?

- Professional knowledge understandings?

Industry understandings?

$\checkmark$ Problem solving techniques?

- Do such differences among employees affect the smooth running of the primary value creating activity of the joint venture?

- Employee communication?

$\checkmark$ Sharing of knowledge and values?

$\checkmark$ Task execution?

\section{Joint Venture Performance}

- Do you think there is an influential relationship between the smooth running of the primary value creating activity and the performance of the joint venture?

(The below questions are designed for individual partners or their representatives)

- What are the strategic objectives that you hope to achieve from the joint venture?

- Are you satisfied with the overall performance of the joint venture?

- Have your strategic objectives changed since the formation of this joint venture?

- If changed, then what are your original expectations?

$\checkmark$ What have caused such changes?

- To what extent have you reached your ultimate strategic objectives?

- How satisfied are you with the current running of the joint venture?

\section{Final Details}

(Final details concerns with financial and market information. Participants may or may not answer these questions)

- What is your annual turnover?

$\checkmark$ Is this growing? At what rate?

- How satisfied are you with the current annual turnover?

$\checkmark$ Is this what you have originally hoped for?

- What is your current market share? 
- How satisfied are you with the current market share?

$\checkmark$ Is this what you have originally hoped for?

\section{Questions for a random selection of partner employees involved in the primary value creating activity of the joint venture:}

\section{Partner employees' professional culture differences}

- Do you think there are differences between the way you work and employees from the other partner?

$\checkmark$ Your work values?

Work/profession related understandings?

$\checkmark$ Problem solving approaches?

- Do you think these differences have considerable effects over you work efficiency?

Does it affect the way you do your job?

- Does it affect the smooth running of the primary value creating activity?

- Does it affect the sharing and learning of related knowledge?

$\checkmark$ Does it affect problem solving?

- Do you think different professional cultures exist between partners' employees?

- How effective is the interaction and communication between partners' employees?

$\checkmark$ Within work?

$\checkmark$ Outside of work?

- Do you think the degree of interaction and communication between partners' employees are influenced by differences in work/profession related understandings and values?

\section{Industry and related professional understanding}

- How long have you worked in this industry?

- What is your industry related training history?

$\checkmark$ Does the amount of training or involvement in the industry positively influence the degree of your professional understandings?

- Before this job, did you work in local manufacturing firms or manufacturing joint ventures?

- Do you find there are differences in understandings, knowledge, and values between partners' employees?

- Is it difficult for you to adjust to an international joint venture work environment?

- Is it difficult to share and learn different knowledge between partner employees?

- Is it difficult to adjust to different work and problem solving methods?

- Do employees with lesser past professional involvement in the industry adjust more easily to new environments? More effective in knowledge sharing and learning between partner employees? 


\section{Appendix 2:}

\section{Victoria

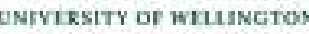 \\ Te Whare Winnsigi \\ o fe Upoko o te lka a Mirmif

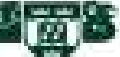

\section{Research Project: Professional culture compatibility and performance in international joint ventures: A China experience}

\section{RESEARCH AGREEMENT}

- This is a research agreement with you personally.

- Your interview will be confidential: that is, no material that identifies you will be published (inside or outside the organisation).

- You will be given an opportunity to review the transcribed interview on which any subsequent analysis will take place.

- No-one will have access to the tapes or notes except for the researcher.

- You will be provided with an information sheet about the project.

- A final summary report is also available.

\section{Participant's statement}

I am satisfied with the information that I have been provided about the project. I realise I can decide not to be involved at any time prior to the completion of the

\section{Participant:} analysis without having to say why.

Name:

Signature: Date:

\section{Researcher:}

Name

Signature: Date:

\section{Contact Details:}

\section{Johnny Gan}

Han Fei Qing Nian Cheng, Yong Qing Road, Apartment 650, Jiang Han District, Wuhan City, Hubei Province, P.R China. Tel.: 008613871463609

Email: gan.xian@student.vuw.ac.nz

\section{Dr. Urs Daellenbach}

RH 1204, Victoria Management School, 23 Lambton Quay, Wellington

Phone: +64-4-463-5732

Email: Urs.Daellenbach@vuw.ac.nz 
Appendix 3:

Victoria

UNIVIRSITY of WMIINGTON

Te Whare Wänigir

o fe llpoko o te lke a Mầi

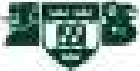

\section{Information Handout}

\section{Professional culture compatibility and performance in international joint ventures: A China experience}

\section{Overview}

Joint ventures represent the most popular form of foreign investments in China, and such forms are growing rapidly. This research project aims to understand international joint ventures in China. More specifically, this project aims to explore professional culture differences between partners' employees in Sino-Foreign joint ventures in China, and the influence of professional culture compatibility on the joint venture performance. With limited past research in this area, this project is generally exploratory in nature. To explore the influence of professional culture on international joint venture performance, this project will analysis and compare a small sample of different joint venture cases. Interviews with all partners and partner employees in these joint ventures will be employed as the data collection method. This research project is part of a thesis for the completion of the Master's of Management studies.

\section{Project Value}

This project consist both theoretical and practical values. In theory, this research will provide additional knowledge to current studies on partner culture compatibility in international alliances. In addition, the concept of professional culture compatibility between partners is relatively new, and has received little attention. Therefore this research will contribute to further understandings in this area, and will provide a foundation for more accurate researches in the future. As for practical values, this research will offer practitioners insights on current joint venture conditions in China. In addition, this research will provide a rich and descriptive analysis on the effect of professional culture on joint venture performance in China. Thus such descriptive results can offer new thinking and ideas to managers when analysing cultural issues in international joint ventures.

\section{Research Process}

In-depth analysis of four international joint venture cases in China will be conducted. This research focus on partner cultures between international joint ventures. For comparative reasons, two cases on Sino - Eastern joint ventures and two cases on Sino - Western joint ventures in China will be conducted and analysed. Within each 
joint venture case, I will interview all joint venture partners (or their representatives) and a small number of randomly selected sample of employees from each partner (2-4 employees in total per joint venture). All interview contents, including individual and organizational names will be kept strictly confidential. I will have the participants to verify my tape transcripts or interview notes to assure reliability. Any audiotapes or notes, once transcribed, will be destroyed or erased. All transcripts, tapes and notes will be stored securely (without any identifying information in the electronic transcripts). Participants can withdraw from this project anytime prior to the completion of data analysis (one moth after the interview). A final report can be sent out to participants on request.

The researcher

My name is Johnny Gan, and I'm the only person conducting this research. I am currently studying Master's of Management Studies in the Victoria University of Wellington, New Zealand. Dr. Urs Daellenbach is my supervisor, lecturing in the Victoria Management School.

\section{Contact Details}

Johnny Gan

Han Fei Qing Nian Cheng, Yong Qing RH 1204, Victoria Management School,

Road, Apartment 650, Jiang Han District, 23 Lambton Quay, Wellington

Wuhan City, Hubei Province, P.R China. Phone: +64-4-463-5732

Tel.: 008613871463609

Email: gan.xian@student.vuw.ac.nz
Dr. Urs Daellenbach

Email: Urs.Daellenbach@vuw.ac.nz 